AUTARQUIA ASSOCIADA À UNIVERSIDADE DE SÃO PAULO

SISTEMA DE CAPTURA DE AEROSSÓIS GERADOS EM ABLAÇÃO COM LASER PARA AMOSTRAGEM DE SUPERFÍCIES CONTAMINADAS

Rodrigo Bohac Ferreira da Rosa

Dissertação apresentada como parte dos requisitos para obtenção do Grau de Mestre em Ciências na Área de Tecnologia Nuclear - Reatores

Orientador:

Prof. Dr. Thadeu das Neves Conti 
INSTITUTO DE PESQUISAS ENERGÉTICAS E NUCLEARES

Autarquia associada à Universidade de São Paulo

\section{SISTEMA DE CAPTURA DE AEROSSÓIS GERADOS EM ABLAÇÃO COM LASER PARA AMOSTRAGEM DE SUPERFÍCIES CONTAMINADAS}

Rodrigo Bohac Ferreira da Rosa

Dissertação apresentada como parte dos
requisitos para obtenção do Grau de
Mestre em Ciências na Área
de Tecnologia Nuclear-Reatores
Orientador:

Prof. Dr. Thadeu das Neves Conti

Versão Corrigida

Versão Original disponível no IPEN

São Paulo

2018 


\section{AGRADECIMENTOS}

Agradeço ao meu orientador, o professor Thadeu Conti, pela atenção, paciência e disposição em me auxiliar ao longo deste mestrado. Agradeço ao idealizador deste trabalho, o professor Roberto Vicente, da Gerência de Rejeitos Radioativos do IPEN, pelo generoso suporte oferecido. Agradeço a Deus, aos meus pais e a minha esposa. 


\title{
SISTEMA DE CAPTURA DE AEROSSÓIS GERADOS EM ABLAÇÃO COM LASER PARA AMOSTRAGEM DE SUPERFÍCIES CONTAMINADAS
}

\section{Rodrigo Bohac Ferreira da Rosa}

RESUMO

\begin{abstract}
A Gerência de Rejeitos Radioativos do IPEN já se utiliza da técnica de ablação por laser para descontaminação de peças superficialmente contaminadas por material radioativo. Esta tecnologia, porém, demonstrou grande potencial para caracterização destes rejeitos com o objetivo de levantar o Inventário Radioisotópico de peças. As técnicas atuais para levantar este inventário (esfregaço e modelagem físico-matemática) sofrem de grandes limitações de implementação e de precisão. O objetivo deste trabalho é desenvolver o projeto de uma sonda de ablação por laser acoplada a um módulo de sucção e captura por filtro do particulado ejetado na ablação, permitindo envio do filtro para análise de emissões radioativas para classificação de radioisótopos.
\end{abstract}

Descritores: Ablação por Laser, Inventário Radioisotópico, Contaminação Radioativa 


\section{CAPTURE SYSTEM OF AEROSOLS GENERATED BY LASER ABLATION FOR RADIOACTIVELY CONTAMINATED SURFACES SAMPLING}

\section{Rodrigo Bohac Ferreira da Rosa}

\section{ABSTRACT}

The department Gerência de Rejeitos Radioativos (Radioactive Waste Management) from IPEN has already used the laser ablation technique for superficial decontamination of parts. This technique has also shown great potential for characterization of this waste with the purpose of rising data for the Radioisotopic Inventory of parts. The current techniques for this purpose (wipe sampling and physical modeling) lack the accuracy and practicality. The objective of this study is to develop the project of an instrument of laser ablation engaged with a module for sucking and capturing (by filter) the particulate ejected from the ablation, allowing the filter to be analyzed in laboratory for radioisotopic classification through radioactive emission.

Key Words: Laser Ablation, Radioisotopic Inventory, Radioactive Contamination 


\section{LISTA DE TABELAS}

\section{Página}

Tabela 1 - Limites de determinação dos radionuclídeos em amostras de rejeito radioativo do IPEN 20

Tabela 2 - Níveis máximos de contaminação radioativa removível na superfície do volume de rejeito radioativo.

Tabela 3 - Cálculo da área mínima de amostragem para detecção de cada radionuclídeo 24

Tabela 4 - Fórmula para cálculo de área e velocidades médias 32

Tabela 5 - Perda de carga localizada 39

Tabela 6 - Perdas de carga distribuídas. 40 


\section{LISTA DE FIGURAS}

Página

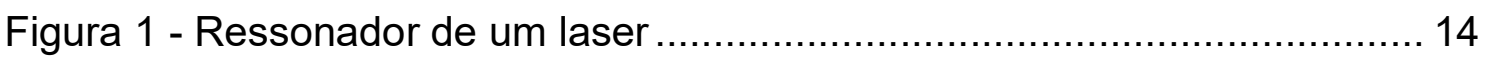

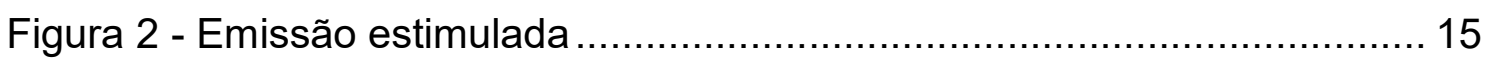

Figura 3 - Esquema de funcionamento do laser ........................................... 16

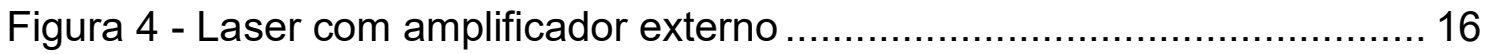

Figura 5 - Princípio de funcionamento da sonda de amostragem ................... 17

Figura 6 - Dimensões da superfície de amostragem e do bocal..................... 27

Figura 7 - Entradas de ar auxiliares para proteção do aparato ótico ................. 28

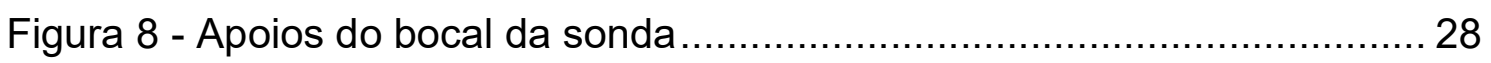

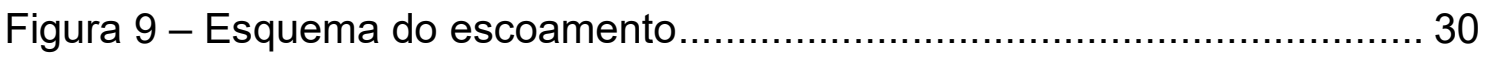

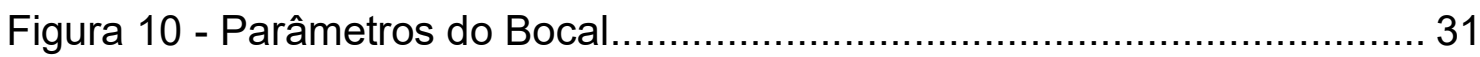

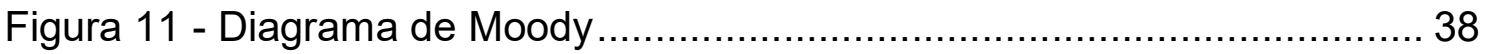

Figura 12 - Perda de carga no filtro FP47M.............................................. 39

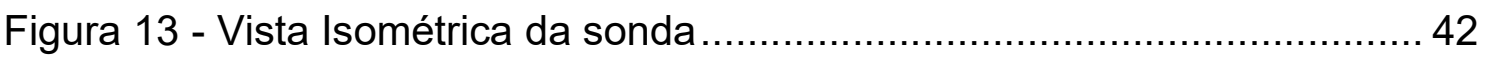

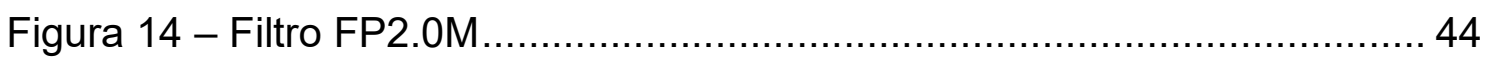

Figura 15 - Suporte de engate rápido do filtro HEPA em disco ......................... 44

Figura 16 - Aspirador de pó Black and Decker AP2000 …............................ 45

Figura 17 - Sistema de filtragem de segurança............................................... 47

Figura 18 - Tamanho de partícula arrastada em função da densidade .............51

Figura 19 - Impacto da esfericidade no arraste de partículas........................... 52 


\section{SUMÁRIO}

Página

1. INTRODUÇÃO

1.1. Física Nuclear e Radioatividade ....................................................... 11

1.2. A Indústria Nuclear e Geração de Resíduos ...................................... 11

1.3. Uso do Laser no Gerenciamento de Resíduos ................................ 12

1.4. Introdução ao Laser ...................................................................... 14

1.4.1 Funcionamento do Laser ......................................................... 15

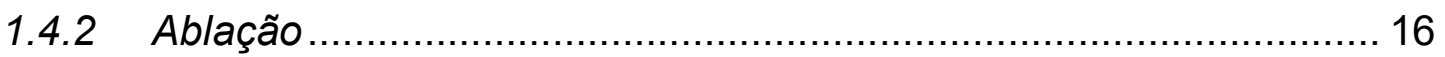

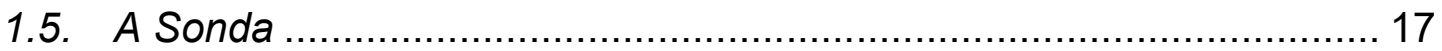

2. OBJETIVOS

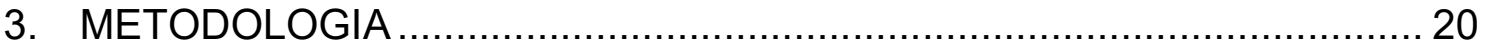

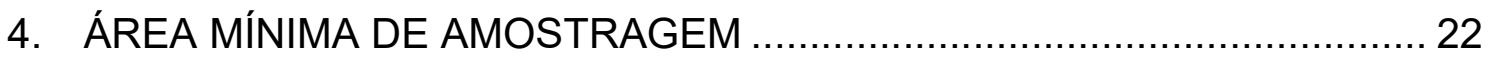

5. CARACTERÍSTICAS DO MATERIAL EJETADO NA ABLAÇÃO................25

6. CARACTERÍSTICAS DA SONDA DE AMOSTRAGEM ............................27

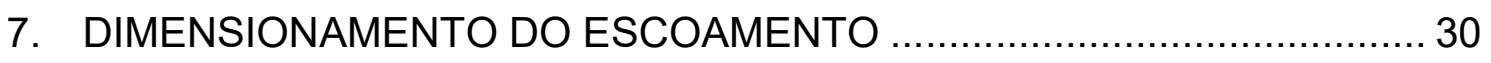

7.1 Velocidades Médias do Escoamento no Circuito ................................ 31

7.2 Fluidodinâmica de Sistemas Particulados.......................................... 32

7.2.1 Efeito de Concentração e de Parede no Escoamento Particulado .. 33

7.2.2 Cálculo do Arraste de Partículas no Escoamento............................ 34

7.3 Perdas de Carga e Potência da Bomba ............................................. 36

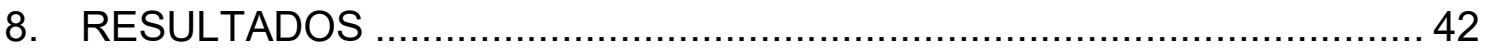

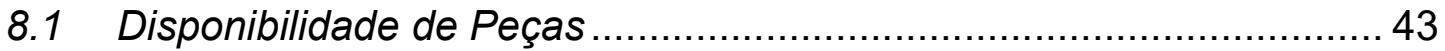

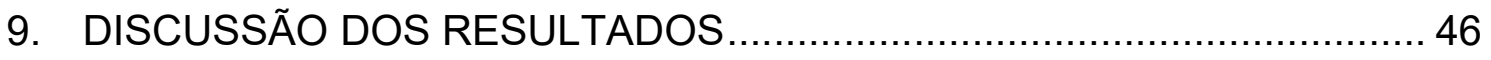

9.1 Instruções de Operação e Segurança............................................... 46 


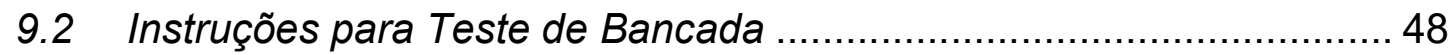

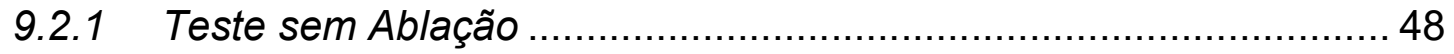

9.2.2 Teste com Ablação de Peça não Contaminada ................................ 48

9.2.3 Teste com Ablação de Peça Contaminada Conhecida ..................... 49

9.2.4 Teste de Consistência de Resultado a Longo Prazo ........................ 49

9.3 Materiais Diversos da Peça Ablacionada e Eficiência da Sucção ....... 50

9.4 Sensibilidade dos Parâmetros de Projeto ………………………....... 53

9.4.1 O Caso de Particulado não Arrastado .............................................. 53

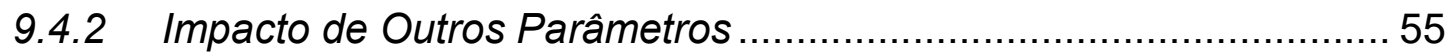

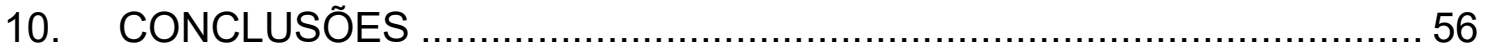

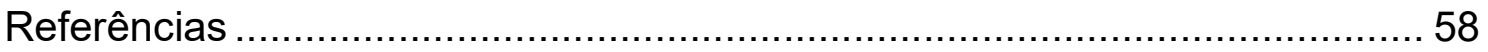

APÊNDICE I - DESENHO DE CONJUNTO DA SONDA ................................. 61

APÊNDICE II - DESENHOS DE FABRICAÇÃO DAS PEÇAS DA SONDA......63 


\section{INTRODUÇÃO}

\subsection{Física Nuclear e Radioatividade}

A Física Nuclear é um ramo da ciência contemporânea que estuda o núcleo atômico e os fenômenos associados a ele. Sua aplicação mais conhecida é a geração de energia nuclear embora que esta aplicação seja apenas uma fração do potencial que a tecnologia nuclear representa para diversas áreas.

Enquanto a teoria atômica se desenvolveu, a descoberta da radioatividade abriu uma nova e rica ramificação da física nuclear, a física das radiações, que tentava explicar e entender a radiação, suas conseqüências e suas implicações.

A radioatividade é o resultado do processo de estabilização de núcleos com excesso de energia (núcleos instáveis), seja por excitação, excesso de partículas ou excesso de carga. Este processo de estabilização se chama decaimento, pois o núcleo atômico tende a cair para um estado menor de energia - e, portanto, mais estável. Os principais tipos de decaimento são:

- Decaimento Alfa;

- Decaimento Beta (-);

- Decaimento Beta (+);

- Decaimento por emissão de cluster;

- Decaimento por captura eletrônica;

- Decaimento Gama;

- Fissão espontânea.

\subsection{A Indústria Nuclear e Geração de Resíduos}

Um dos processos de decaimento que mais chamou a atenção dos pesquisadores foi o de Fissão Espontânea devido à grande liberação de energia em seu processo. Esta foi a base científica do desenvolvimento das usinas nucleares, que têm por finalidade a geração de energia elétrica. 
O Urânio-235 é o nuclídeo físsil mais utilizado como combustível em reatores nucleares. Além dele, também são utilizados Urânio-233 e Plutônio239, sendo estes artificiais. Analisando os produtos de fissão do Urânio-235, notou-se que a faixa de números de massa destes produtos varia de 66 , correspondendo a um isótopo de Crômo, até 172, um isótopo do Gadolínio. Assim mostrou-se que o Urânio-235 pode se dividir em até 107 nuclídeos diferentes. [1]

Entretando, a população de nuclídeos encontrados no resíduo do combustível nuclear após a sua queima não se limita aos fragmentos de fissão diretos. Os fragmentos diretos da fissão possuem, de uma forma geral, excesso de nêutrons e iniciam uma cadeia de decaimento, com geralmente seis ou sete membros até a estabilidade [1]. Todos estes membros, em maior ou menor proporção, constituem o resíduo final. Deve-se destacar que este resíduo do reator apresenta alta atividade radioativa, uma vez que é formado em sua maior parte por nuclídeos instáveis em pleno processo de decaimento radioativo.

A maior parte do resíduo é retirada do núcleo do reator e depositada em grandes tanques de armazenamento, entretanto uma pequena parcela fica incrustada em peças com que entraram em contato. Para o descarte adequado destes equipamentos contaminados, é necessária a avaliação de seu inventário radioisotópico. O inventário radioisotópico é a lista de todos os radioisótopos presentes no equipamento e suas respectivas concentrações.

\subsection{Uso do Laser no Gerenciamento de Resíduos}

Os centros de pesquisa e desenvolvimento do IPEN, Gerência de Rejeitos Radioativos (GRR) e Centro de Lasers e Aplicações (CLA), estão empenhados em desenvolver a tecnologia de ablação por laser como ferramenta para a descontaminação radioativa superficial de objetos [2].

A ablação por laser é não só eficiente em remover a contaminação como também apresenta vantagens sobre métodos tradicionais [3] [4] [5] [6] [7]. É extensa a lista de benefícios do uso de lasers para o tratamento de rejeitos radioativos de descomissionamento: 
a. melhora a segurança das operações;

b. diminui a geração de rejeitos secundários;

c. reduz a contaminação de equipamentos usados no tratamento;

d. dispensa o uso de produtos químicos perigosos;

e. reduz os custos totais devido menor volume de rejeito.

Não bastasse a ablação por lasers ser tão atrativa para o tratamento de rejeitos radioativos por descontaminação de superfícies contaminadas, ela tem grande potencial para ser um instrumento muito útil para a caracterização dos rejeitos. Com uma caracterização apropriada, se pode garantir uma gestão segura e com a qualidade exigida pela legislação e recomendada nos padrões de boas práticas dos órgãos internacionais [8].

Uma das propriedades dos rejeitos que a ablação por laser pode auxiliar na determinação é o inventário radioisotópico. Esse inventário, ou como é também chamado, ativo isotópico, é a relação de todos os radioisótopos relevantes presentes e suas respectivas concentrações de atividade. Ele pode ser obtido por modelagem matemática dos processos físicos e químicos que deram origem aos rejeitos, mas, em geral, é obtido pela amostragem e pela aplicação de métodos radioquímicos de análise, seguidos da utilização da análise estatística apropriada para determinar os valores e as incertezas dos resultados [9].

Os padrões de segurança da Agência Internacional de Energia Atômica requerem que o conteúdo radioativo seja conhecido para que se possam classificar os rejeitos[10], para que se possa definir o tipo de tratamento [11] o armazenamento [12] e os critérios de aceitação na deposição [13]. Serve também para estabelecer os planos de segurança durante 0 manuseio dos rejeitos [14] e durante as fases operacionais [15] e pósencerramento dos repositórios [16]. Por fim, mais importante que tudo, a caracterização é um requisito regulatório [17].

O método usual de se obter amostras de superfícies contaminadas é a amostragem por esfregaço [18], com o qual a área a ser amostrada é esfregada com um disco de papel ou tecido absorventes. O disco é então colocado no receptáculo apropriado de um detector de esfregaço e 'contado' pela detecção das emissões alfa, beta ou gama. $O$ esfregaço pode ser também 
enviado a um laboratório onde os radioisótopos presentes são determinados pelos métodos radioquímicos usuais.

O método de amostragem por esfregaço, o mais tradicional, embora muito utilizado, sofre de limitações, podendo ser impreciso e inexato devido à inconstância do operador, dificuldade de estabelecer uma área de amostragem precisa e impossibilidade de captar resíduos fortemente aderidos à peça [19] [20] [21] [22] [23]. A amostragem por ablação com laser é, portanto, um método de amostragem que apresenta desempenho superior ao método convencional e seu desenvolvimento é oportuno.

\subsection{Introdução ao Laser}

A palavra laser vem do acrônimo em inglês "light amplification by stimulated emission of radiation" que significa amplificação de luz por emissão estimulada de radiação. De uma forma geral, em um equipamento laser, insere-se energia (elétrica, normalmente) e luz é produzida.

Existem três características que destacam o laser dos demais tipos de luz. Primeira: o raio de luz laser é muito mais estreito que o raio de luz comum. O laser é a forma de luz que apresenta a menor divergência possível devido ao seu perfil de intensidade seguir a curva de Gauss (intensidade da luz é concentrada no centro do raio e é suavizada nas bordas). Além disto, no ressonador, os fótons são contidos entre dois espelhos e são refletidos de um para outro até saírem pelo feixe final do laser, como pode ser visto na Figura 1. Fótons não alinhados com o eixo do ressonador são absorvidos pelas paredes do ressonador.

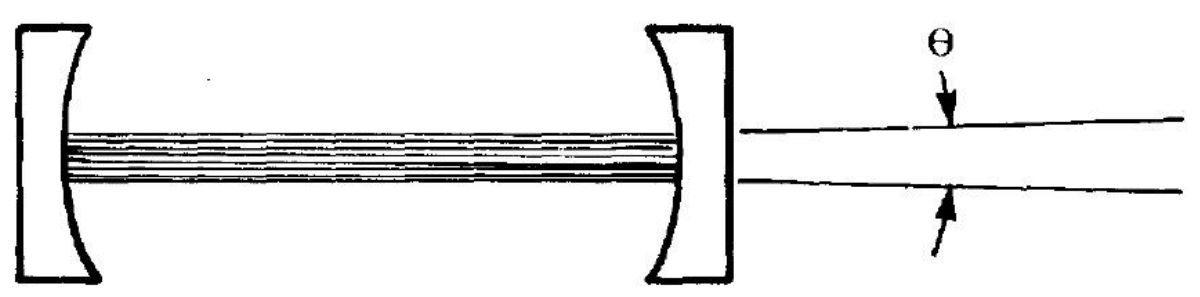

Figura 1 - Ressonador de um laser [24] 
Segunda: o laser contém apenas uma cor pura (ou o mais próximo de uma cor pura possível). Este monocromatismo do laser é resultado do processo de geração do laser, que é a emissão estimulada de luz.

Terceira: As ondas de luz do laser estão em concordância de fase, tornando todas as interferências construtivas.

Estas características de monocromatismo e direcionalidade, juntas com a consistente concordância de fase do laser, são combinadas em um único e descritivo termo: coerência. Coerência é o que faz a luz do laser diferente das luzes produzidas por qualquer outra fonte [24].

\subsubsection{Funcionamento do Laser}

O Laser é produzido por um fenômeno chamado emissão estimulada, em que um átomo (ou molécula) previamente excitado, ao interagir com um fóton de uma energia específica, emite um outro fóton com a mesma direção, energia e fase do fóton incidente (vide Figura 2). São os níveis de energia deste átomo/molécula que determinam a cor do laser.

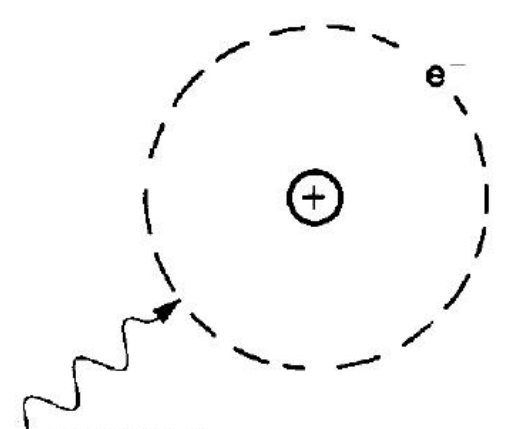

Photon I

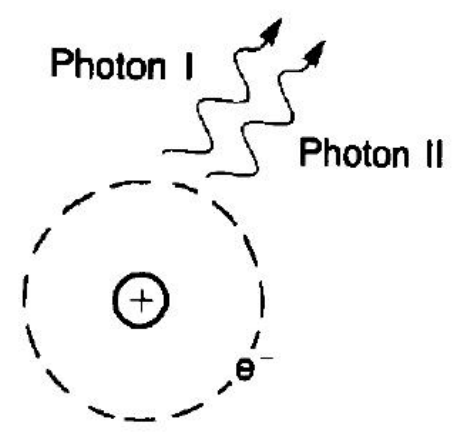

Figura 2 - Emissão estimulada [24]

Este processo ocorre no amplificador, que normalmente é um cristal ou um gás. Este fica dentro do ressonador de forma que os fótons atravessam o amplificador inúmeras vezes, como pode ser visto em esquema na Figura 3. O feixe útil do laser consegue evadir o ressonador devido a parcialidade de reflexão de um dos espelhos. 


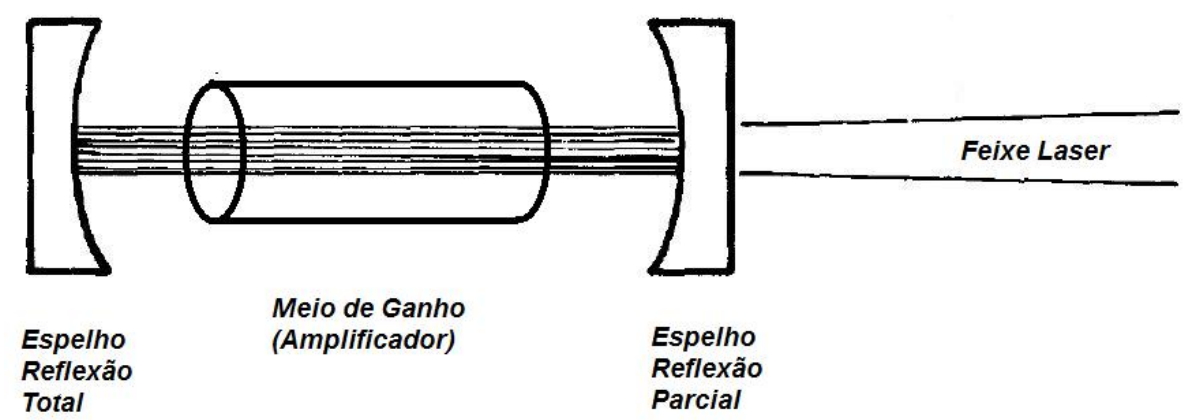

Figura 3 - Esquema de funcionamento do laser ([24], adaptado)

A excitação dos átomos do amplificador é mantida por descargas elétricas ou por uma lâmpada de bombeamento, que basicamente representam o único gasto de energia necessário para manter o laser em funcionamento.

\subsubsection{Ablação}

O processo de ablação é uma descarga muito energética, concentrada e curta de laser sobre a superfície de um material, provocando a quebra das ligações moleculares e uma conseqüente explosão coulombiana.

A ablação é desempenhada por lasers pulsados, em que o feixe de saída é emitido em pulsos. Nestes lasers, há a possibilidade de se inserir um amplificador fora do ressonador (vide Figura 4). Enquanto o feixe do laser não é liberado, o amplificador é "carregado" e quando o pulso é liberado, quase toda energia empenhada na excitação do amplificador é utilizada no processo de emissão estimulada, garantindo um alto valor de potência no feixe pulsado.

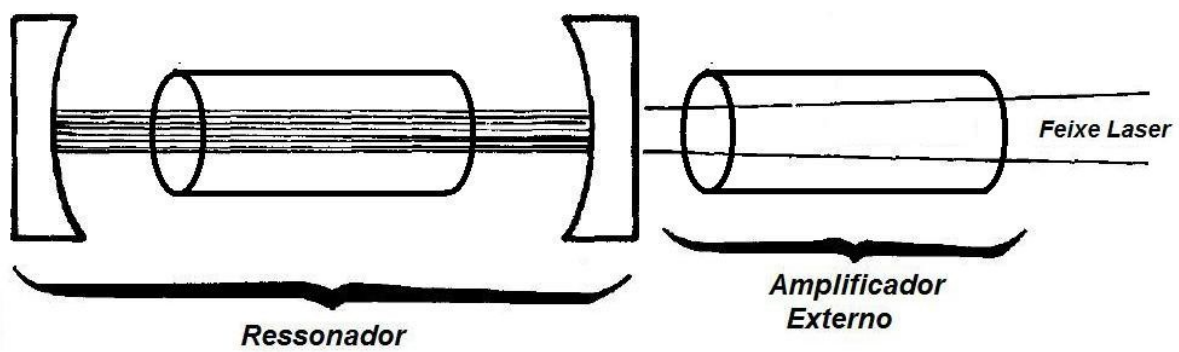

Figura 4 - Laser com amplificador externo ([24], adaptado) 


\subsection{A Sonda}

O instrumento de amostragem (Figura 5) é constituído de duas partes principais: um sistema laser para a ablação da superfície a ser amostrada e um sistema de aspiração e captura do material ejetado. É nesse segundo sistema que o presente plano de trabalho está focado.

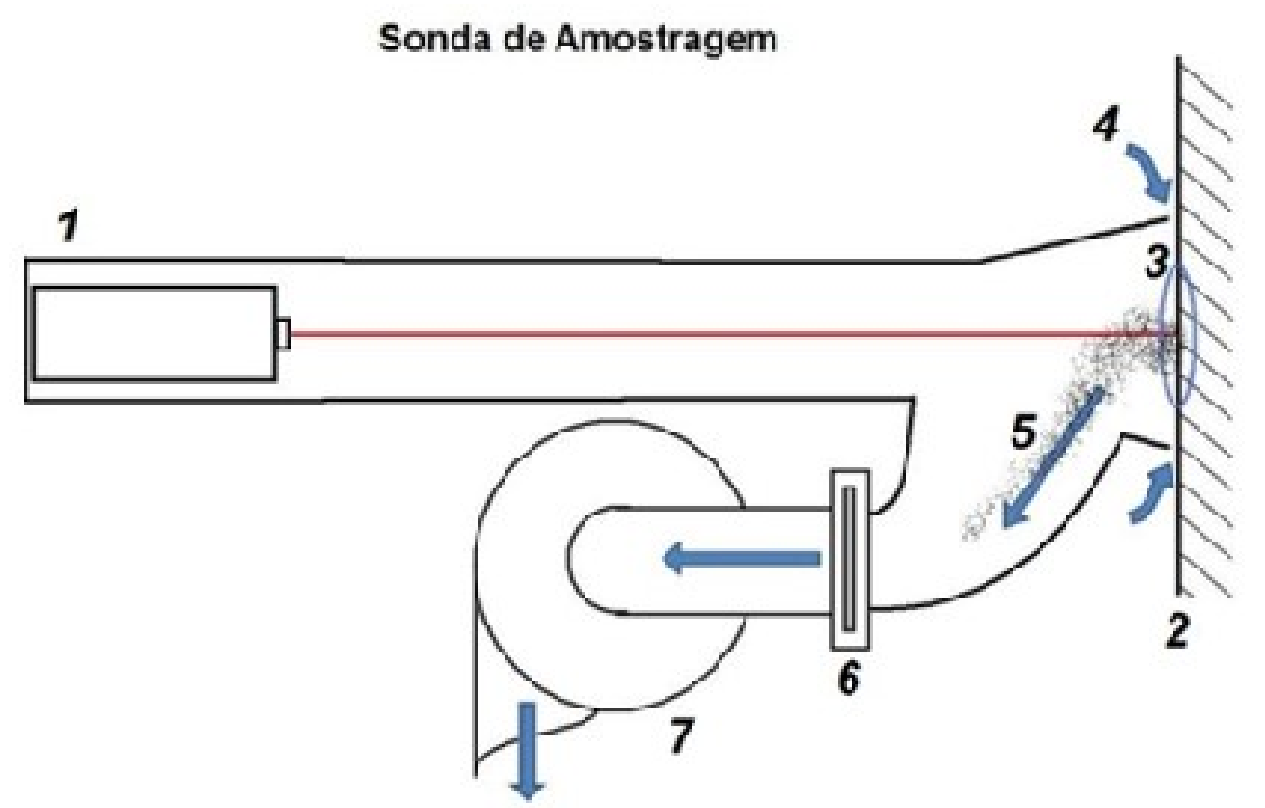

Legenda:

1) laser de ablaçào - desenvolvimento conjunto entre GRR e CLA;

2) superficie da peça contaminada;

3) área de amostragem varrida pelo feixe de laser;

4) fluxo de ar gerado pelo déficit de pressăo (ddp) criado pela bomba de vácuo;

5) particulado ejetado sendo levado pelo fluxo de ar;

6) filtros HEPA (High Efficiency Particulate Air Filters);

7) bomba de vácuo com ddp necessíria à sucçào.

Figura 5 - Princípio de funcionamento da sonda de amostragem [Fonte Própria]

O sistema de aspiração deve ser capaz de operar sob as condições de trabalho previstas para um local de amostragem de rejeitos radioativos; deve ser capaz de recolher aproximadamente $100 \%$ do material ejetado e conduzi-lo para um filtro para aerossóis capaz de capturar porcentagens próximas de 100\% particulado. Eficiências de 99,99\% para partículas de 
aerossóis são usualmente alcançáveis com filtros HEPA (High Efficiency Particulate Air Filters) [25].

O projeto de um sistema de captura do material resultante da ablação pode ser feito com base em parâmetros já fartamente estudados e publicados. Algumas das referências que dão suporte a um projeto de sistema para aspiração do material amostrado são [26] [27] [28]. 


\section{OBJETIVOS}

O objetivo geral deste trabalho é desenvolver o projeto de um equipamento que faça a captura do material ejetado, durante a ablação por laser, de superfícies contaminadas por radionuclídeos, de modo que possa ser analisado química e radiologicamente.

Os objetivos específicos são:

- Determinar as principais propriedades físicas do material ejetado durante a ablação com laser (Exemplo: velocidade de ejeção, distância de parada...);

- Determinar as áreas mínimas das superfícies que devem sofrer ablação para se alcançar os limites de quantificação, de cada radionuclídeo de interesse, pelos métodos radioquímicos usuais;

- Determinar as características da sonda de amostragem, capaz de fazer a captura do material ejetado, para se obter eficiência próxima a $100 \%$;

- Determinar os parâmetros de operação do sistema de aspiração e filtração do material ejetado; 


\section{METODOLOGIA}

Para realização desta pesquisa, o método de trabalho adotado será o seguinte:

a. inicialmente será feito um estudo, na literatura técnica, do fenômeno físico da ablação para se conhecer as propriedades do material ejetado, tais como, velocidades, alcances, temperaturas, distribuição do diâmetro das partículas etc. para diversas condições operacionais do laser e para diferentes materiais e superfícies;

b. A determinação das áreas mínimas das superfícies a sofrerem ablação será feita a partir dos limites de concentração, estabelecidos nos regulamentos nacionais aplicáveis, para dispensa incondicional de rejeitos radioativos, para cada radionuclídeo de interesse [17]. Uma fração adequada, por exemplo 1/10 do limite, será adotado como objetivo de desempenho do sistema. A partir dos limites de quantificação de cada radionuclídeo, pelos métodos radioquímicos usuais alcançados nas análises realizadas pelos laboratórios do IPEN, e os valores alvo de concentração, serão calculados os tamanhos das áreas na superfície dos materiais contaminados. A Tabela 1 contém dados sobre os métodos radioanalíticos empregados e os limites de deteç̧ão (em atividade por massa de amostra - Bq/g, e em concentração mássica $-\mathrm{g} / \mathrm{g})$.

Tabela 1 - Limites de determinação dos radionuclídeos em amostras de rejeito radioativo do IPEN ${ }^{1}$ [29]

[17]

\begin{tabular}{lcccl}
\hline & & \multicolumn{3}{c}{ Limites de determinação (LD) em amostras de rejeito } \\
\cline { 3 - 5 } Radio- & \multirow{2}{*}{$\begin{array}{c}10 * \mathrm{LD} \\
\text { isótopo }\end{array}$} & $\begin{array}{c}10 * \mathrm{LD} \\
\left(\mathrm{Bq} \cdot \mathrm{g}^{-1}\right)\end{array}$ & $\begin{array}{l}\left.\text { (g.g } \mathrm{g}^{-1}\right) \\
\text { Método de }\end{array}$ & \\
\hline $\mathrm{H}-3$ & $1.23 \mathrm{E}+01$ & $1.0 \mathrm{E}+00$ & $2.8 \mathrm{E}-15$ & AutomaticOxidizer+LSC \\
C-14 & $5.73 \mathrm{E}+03$ & $5.0 \mathrm{E}+00$ & $3.0 \mathrm{E}-11$ & AutomaticOxidizer+LSC \\
Fe-55 & $2.73 \mathrm{E}+00$ & $2.0 \mathrm{E}-01$ & $2.3 \mathrm{E}-15$ & HydroxidePrecipit+LSC \\
Ni-59 & $7.50 \mathrm{E}+04$ & $5.7 \mathrm{E}+00$ & $1.9 \mathrm{E}-09$ & ChromatographDMG+LEGeD \\
Ni-63 & $1.00 \mathrm{E}+02$ & $5.5 \mathrm{E}+01$ & $2.6 \mathrm{E}-11$ & ChromatographDMG+LSC \\
Co-60 & $5.27 \mathrm{E}+00$ & $2.0 \mathrm{E}+01$ & $4.8 \mathrm{E}-13$ & GammaSpec
\end{tabular}

\footnotetext{
${ }^{1}$ Comunicação pessoal, fornecida por Vicente, R., em São Paulo, 2016.
} 


\begin{tabular}{lllll} 
Sr-90 & $2.86 \mathrm{E}+01$ & $5.0 \mathrm{E}+00$ & $9.8 \mathrm{E}-13$ & ChromatographSeparat+LSC \\
Tc-99 & $2.10 \mathrm{E}+05$ & $5.0 \mathrm{E}+00$ & $7.9 \mathrm{E}-09$ & TEVAResinSeparation+LSC \\
Ag-108m & $4.18 \mathrm{E}+02$ & $1.7 \mathrm{E}+00$ & $5.8 \mathrm{E}-12$ & AgClPrecipitation+SPECG \\
Cs-137 & $3.02 \mathrm{E}+01$ & $2.0 \mathrm{E}+01$ & $6.3 \mathrm{E}-12$ & GammaSpec \\
Pb-210 & $2.23 \mathrm{E}+01$ & $5.4 \mathrm{E}-02$ & $2.2 \mathrm{E}-14$ & PbCrO4Cooprec+TotalBetaCount \\
Ra-226 & $1.60 \mathrm{E}+03$ & $3.6 \mathrm{E}-02$ & $1.1 \mathrm{E}-12$ & BaSO4Cooprecipit+TotalAlphaCount \\
Ra-228 & $5.75 \mathrm{E}+00$ & $5.4 \mathrm{E}-02$ & $5.8 \mathrm{E}-15$ & BaSO4Cooprecipit+TotalBetaCount \\
U-234 & $2.46 \mathrm{E}+05$ & $2.0 \mathrm{E}-02$ & $8.7 \mathrm{E}-11$ & UTEVAResin+AlphaSpec \\
U-235 & $7.04 \mathrm{E}+08$ & $2.0 \mathrm{E}-02$ & $2.5 \mathrm{E}-07$ & UTEVAResin+AlphaSpec \\
U-238 & $4.47 \mathrm{E}+09$ & $2.0 \mathrm{E}-02$ & $1.6 \mathrm{E}-06$ & UTEVAResin+AlphaSpec \\
Np-237 & $2.14 \mathrm{E}+06$ & $2.0 \mathrm{E}-02$ & $7.7 \mathrm{E}-10$ & Ion-Exchange+AlphaSpec \\
Pu-238 & $8.77 \mathrm{E}+01$ & $2.0 \mathrm{E}-02$ & $3.2 \mathrm{E}-14$ & Ion-Exchange+AlphaSpec \\
Pu-239 & $2.40 \mathrm{E}+04$ & $2.0 \mathrm{E}-02$ & $8.7 \mathrm{E}-12$ & Ion-Exchange+AlphaSpec \\
Pu-240 & $6.56 \mathrm{E}+03$ & $2.0 \mathrm{E}-02$ & $2.4 \mathrm{E}-12$ & Ion-Exchange+AlphaSpec \\
Pu-241 & $1.44 \mathrm{E}+01$ & $1.0 \mathrm{E}+01$ & $2.6 \mathrm{E}-12$ & Ion-Exchange+LSC \\
Am-241 & $4.32 \mathrm{E}+02$ & $2.0 \mathrm{E}-02$ & $1.6 \mathrm{E}-13$ & TRUSpecificResin+AlphaSpec \\
Cm-243 & $2.91 \mathrm{E}+01$ & $2.0 \mathrm{E}-02$ & $1.1 \mathrm{E}-14$ & TRUSpecificResin+AlphaSpec \\
Cm-244 & $1.81 \mathrm{E}+01$ & $2.0 \mathrm{E}-02$ & $6.7 \mathrm{E}-15$ & TRUSpecificResin+AlphaSpec \\
\hline & & & &
\end{tabular}

C. A partir das características do material ejetado e dos resultados do item anterior, serão determinadas as características da sonda de amostragem, tais como dimensões, geometria do instrumento em relação à superfície sob ablação, velocidade mínima de arraste do material ejetado, material de construção do instrumento; acabamento requerido para as superfícies do instrumento etc.;

d. Em função dos resultados dos itens anteriores, serão escolhidos no mercado, isto é, como elementos padronizados encontrados em catálogos de fornecedores, os seguintes equipamentos: filtros especiais HEPA para captura de material ejetado das superfícies contaminadas durante a ablação; bomba de vácuo com vazão volumétrica e perda de carga suficientes para fazer a sucção de todo o material ejetado; acessórios e outros dispositivos menores. 


\section{4. ÁREA MÍNIMA DE AMOSTRAGEM}

A norma CNEN NN 8.01 - Gerência de Rejeitos Radioativos de Baixo e Médio Níveis de Radiação - apresenta a Tabela 2 com os limites de contaminação superficial para o descarte comum.

Tabela 2 - Níveis máximos de contaminação radioativa removível na superfície do volume de rejeito radioativo [17]

\begin{tabular}{|c|c|}
\hline \multicolumn{2}{|c|}{ RADIONUCLÍDEO CONTAMINANTE } \\
\hline Emissores $\beta$ e $\gamma$, e emissores $\alpha$ de baixa toxicidade & Todos os outros emissores $\alpha$ \\
\hline $\mathrm{Bq} / \mathrm{m}^{2}$ & $\mathrm{~Bq} / \mathrm{m}^{2}$ \\
\hline $4.10^{4}$ & $0.4 \cdot 10^{4}$ \\
\hline
\end{tabular}

Supondo que todo material ejetado na ablação seja capturado pelo sistema de filtragem, pode se desenvolver para cada radionuclídeo as seguintes fórmulas para encontrar a área mínima de amostragem:

$$
a_{e}=C_{s} A_{m}
$$

$a_{e}-$ atividade do radionuclídeo na massa ejetada $(\mathrm{Bq})$;

$C_{s}$ - Concentração superficial de atividade do radionuclídeo na peça $\left(\mathrm{Bq} / \mathrm{m}^{2}\right)$;

$A_{m}-$ Área de amostragem da sonda $\left(\mathrm{m}^{2}\right)$.

$$
c=\frac{a_{e}}{m_{e}+m_{f}}
$$

$c$ - concentração de atividade do radionuclídeo no filtro $(\mathrm{Bq} / \mathrm{kg})$;

$m_{e}$ - massa ejetada na ablação $(\mathrm{kg})$;

$m_{f}$ - massa do filtro hepa limpo $(\mathrm{kg})$;

$\mathrm{Na}$ situação crítica para detecção do radionuclídeo, este possui exatamente o nível máximo de contaminação radioativa superficial da norma $\left(C_{s l i m}\right)$.

$$
C_{s}=C_{\text {sim }}
$$


Como condição para que seja detectado pelos laboratórios do IPEN - dentro da margem de segurança de $10 x$ - a concentração de atividade do radionuclídeo no filtro deve atender o seguinte:

$$
c>L d_{10}
$$

$L d_{10}-10 \times$ Limite de determinação $(L d)$ do radionuclídeo $(\mathrm{Bq} / \mathrm{kg})$;

Combinando as fórmulas acima, é possível deduzir uma única e final fórmula para determinação da Área Mínima de Amostragem $\left(A_{\min }\right)$ para cada radionuclídeo:

$$
A_{\min }=L d_{10} \frac{m_{e}+m_{f}}{C_{s l i m}}
$$

Uma vez que a massa ejetada na ablação é desprezível frente à massa do filtro vazio $\left(m_{e}<<m_{f}\right)$, pode-se considerar que a massa da amostra levada ao laboratório é apenas $m_{f}$. Ou seja, $m_{e}+m_{f}=\sim m_{f}$. Assim, a fórmula da área mínima de amostragem se reduz à seguinte:

$$
A_{\min }=\frac{L d_{10} m_{f}}{C_{\text {slim }}}
$$

Uma vez calculada a área mínima de amostragem para cada um dos nuclídeos, deve-se adotar a maior delas para assegurar que todos os nuclídeos sejam detectados. A relação dos nuclídeos com suas áreas mínimas de amostragem pode ser observada na Tabela 3: 
Tabela 3 - Cálculo da área mínima de amostragem para detecção de cada radionuclídeo [Fonte Própria]

\begin{tabular}{|c|c|c|c|}
\hline Radioisótopo & $\begin{array}{c}\text { Limites de } \\
\text { determinação (LD) } \\
\text { em amostras de } \\
\text { rejeito }\end{array}$ & $\begin{array}{c}\text { Tipo de } \\
\text { Decaimento }\end{array}$ & $\begin{array}{c}\text { Níveis } \\
\text { máximos de } \\
\text { contaminação } \\
\text { radioativa } \\
\text { removível na } \\
\text { superfície do } \\
\text { volume de } \\
\text { rejeito } \\
\text { radioativo } \\
\left(\mathrm{Bq} / \mathrm{m}^{2}\right)\end{array}$ \\
\hline $\mathrm{H}-3$ & $1,00 E+00$ & beta- & 40000 \\
\hline$C-14$ & $5,00 E+00$ & beta- & 40000 \\
\hline $\mathrm{Fe}-55$ & 2,00E-01 & EC+ beta+ & 40000 \\
\hline $\mathrm{Ni}-59$ & $5,70 \mathrm{E}+00$ & $\mathrm{EC}+$ beta+ & 40000 \\
\hline $\mathrm{Ni}-63$ & $5,50 \mathrm{E}+01$ & beta- & 40000 \\
\hline Co-60 & $2,00 \mathrm{E}+01$ & beta- & 40000 \\
\hline Sr-90 & $5,00 E+00$ & beta- & 40000 \\
\hline Tc-99 & $5,00 E+00$ & beta- & 40000 \\
\hline Ag-108m & $1,70 \mathrm{E}+00$ & beta- & 40000 \\
\hline Cs-137 & $2,00 E+01$ & beta- & 40000 \\
\hline $\mathrm{Pb}-210$ & $5,40 \mathrm{E}-02$ & beta- & 40000 \\
\hline Ra-226 & $3,60 \mathrm{E}-02$ & alpha & 4000 \\
\hline Ra-228 & $5,40 \mathrm{E}-02$ & beta- & 40000 \\
\hline U-234 & $2,00 \mathrm{E}-02$ & alfa & 4000 \\
\hline U-235 & $2,00 \mathrm{E}-02$ & alfa * & 40000 \\
\hline $\mathrm{U}-238$ & $2,00 \mathrm{E}-02$ & alfa * & 40000 \\
\hline Np-237 & $2,00 \mathrm{E}-02$ & alfa & 4000 \\
\hline Pu-238 & $2,00 \mathrm{E}-02$ & alfa & 4000 \\
\hline Pu-239 & $2,00 \mathrm{E}-02$ & alfa & 4000 \\
\hline Pu-240 & $2,00 \mathrm{E}-02$ & alfa & 4000 \\
\hline Pu-241 & $1,00 \mathrm{E}+01$ & beta- & 40000 \\
\hline Am-241 & $2,00 \mathrm{E}-02$ & alfa & 4000 \\
\hline $\mathrm{Cm}-243$ & $2,00 \mathrm{E}-02$ & alfa & 4000 \\
\hline $\mathrm{Cm}-244$ & $2,00 \mathrm{E}-02$ & alfa & 4000 \\
\hline
\end{tabular}

\begin{tabular}{|c|}
\hline \\
\\
\hline $\begin{array}{c}\text { Área Minima de } \\
\text { Amostragem }\end{array}$ \\
\hline \\
\hline (mm $\left.{ }^{2}\right)$ \\
\hline 4,0 \\
\hline 19,8 \\
\hline 0,8 \\
\hline 22,6 \\
\hline 217,7 \\
\hline 79,2 \\
\hline 19,8 \\
\hline 19,8 \\
\hline 6,7 \\
\hline 79,2 \\
\hline 0,2 \\
\hline 1,4 \\
\hline 0,2 \\
\hline 0,8 \\
\hline 0,1 \\
\hline 0,1 \\
\hline 0,8 \\
\hline 0,8 \\
\hline 0,8 \\
\hline 0,8 \\
\hline 39,6 \\
\hline 0,8 \\
\hline 0,8 \\
\hline \\
\hline \\
\hline \\
\hline \\
\hline
\end{tabular}

* Emissores alfa de baixa toxicidade

Observando a distribuição de valores da tabela acima, nota-se que o radionuclídeo limitante para a determinação da área de amostragem da sonda é o Níquel-63, devido à dificuldade de sua detecção em baixas concentrações. Desta forma, fica determinado que a superfície de amostragem da sonda seja um quadrado de lados $15 \mathrm{~mm}$ e portanto de área $225 \mathrm{~mm}^{2}$ (maior que 217,7 $\mathrm{mm}^{2}$ necessários). A pré-determinada margem de segurança de 10x para os laboratórios de detecção já está considerada neste valor de área. 


\section{CARACTERÍSTICAS DO MATERIAL EJETADO NA ABLAÇÃO}

A maior parte da literatura modela o fenômeno da ablação em atmosfera rarefeita. Felizmente, alguns estudos consideram o meio em pressão ambiente e reportam que o ar tem o papel de confinamento e de atraso da pluma de expansão do plasma, provocando plumas menores que $1 \mathrm{~cm}[30,31]$.

A pluma de plasma é composta por átomos e moléculas em seu estado fundamental, excitado ou ionizado. Sua expansão ocorre principalmente na direção perpendicular à superfície irradiada e a velocidade inicial destas partículas é tipicamente de $10^{5} \mathrm{~cm} / \mathrm{s}[31]$. As altas temperaturas atingidas pelo material ejetado variam conforme duração do pulso do laser, e podem atingir até $60000 \mathrm{~K}$. Entretanto, devido à pequena dimensão e alta velocidade do particulado ejetado, sua temperatura cai rapidamente. A apenas $0,5 \mathrm{~mm}$ de distância da superfície ablacionada, a temperatura reportada já é apenas $20 \%$ do valor máximo [28]. Desta forma, fora da pluma de expansão o particulado já não apresenta temperatura muito superior à ambiente.

Fora da pluma de expansão, são considerados dois tipos de partículas ejetadas na ablação. Partículas de até algumas centenas de nanômetros são resultados do processo de condensação dos átomos ejetados. Partículas ainda maiores são o resultado de seu desprendimento direto da peça ablacionada [32].

Em metais, a forma de ejeção mais comum é por gotas de metal na forma líquida, que são expelidas devido ao impacto da pressão de recuo da pluma [32].

A formação de partículas é fortemente sensível a parâmetros da ablação, principalmente duração do pulso (microsegundos, nanosegundos ou picosegundos), fluência $\left(\mathrm{J} / \mathrm{cm}^{2}\right)$ e irradiação $\left(\mathrm{W} / \mathrm{cm}^{2}\right)$. Logo, há meios de sintonizar estes parâmetros para exercer certo controle do tamanho médio de partícula ejetada. Assim, o que determinará o tamanho das partículas é a necessidade do projeto, levando-se em conta a eficiência do sistema de sucção e filtragem.

Quanto menor o tamanho da partícula ejetada, maior será o efeito do arrasto do escoamento em detrimento de efeitos de inércia e gravidade. Assim, pequenas partículas, mesmo de alta densidade, podem se comportar como 
parte do fluido em escoamento (especialmente em escoamentos turbulentos). Isto é desejado para que todo material ejetado chegue até o filtro e não haja pontos de deposição dentro do bocal. Entretanto, o tamanho de partícula deve atender o limite de captação e eficiência do filtro HEPA. 


\section{CARACTERÍSTICAS DA SONDA DE AMOSTRAGEM}

O bocal da sonda deve possuir o menor diâmetro possível, desde que comporte a área de amostragem e o volume de expansão da pluma de plasma do processo de ablação, para que a vazão de sucção tenha maior impacto de arraste das partículas ejetadas.

Como já determinado no capítulo da área mínima de amostragem, a superfície de amostragem da sonda deverá ser um quadrado de lados 15,0 $\mathrm{mm}$. Considerando o afastamento para pluma de expansão, obtém-se um diâmetro do bocal de 45,0 mm, conforme Figura 6 .

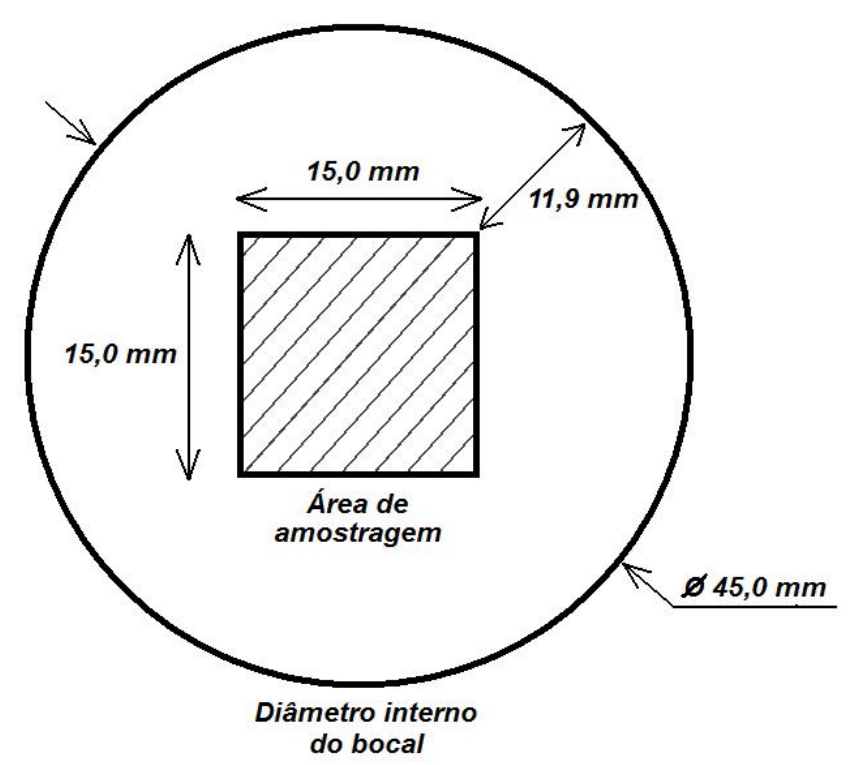

Figura 6 - Dimensões da superfície de amostragem e do bocal [Fonte Própria]

Como a transparência do aparato ótico através do qual o laser entra no bocal é crucial para a integridade do laser, deve-se evitar de forma especial a deposição de material ejetado nesta peça. Uma forma de se conseguir isso seria a formação de uma cortina de ar em alta velocidade ao redor desta por meio de entradas auxiliares de ar na parede do bocal, como pode ser visto na Figura 7. 


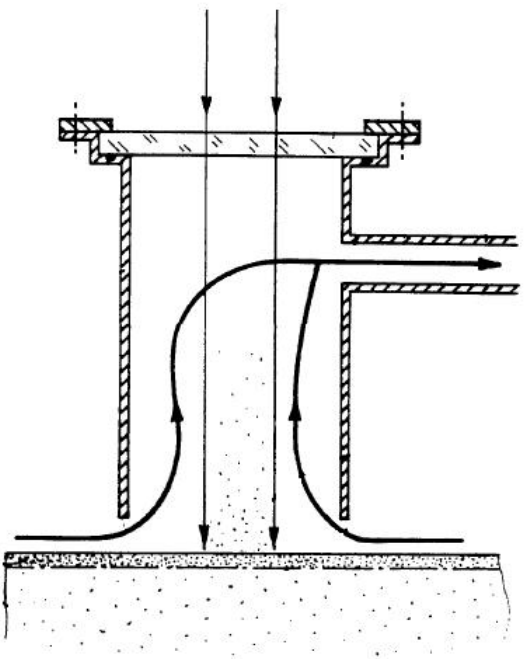

Sem entradas de ar auxiliares

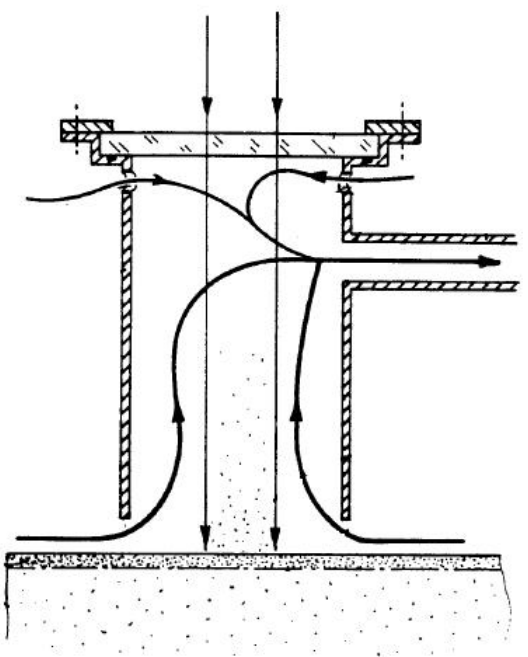

Com entradas de ar auxiliares

Figura 7 - Entradas de ar auxiliares para proteção do aparato ótico. [33, adaptado]

O escoamento será naturalmente turbulento devido à dimensão dos componentes envolvidos e a alta velocidade do ar. Esta turbulência também será vantajosa no sentido de promover uma maior mistura do escoamento e evitar a estabilidade das possíveis bolhas de recirculação que inevitavelmente surgirão. Estas duas características promovidas pela turbulência garantirão grande eficiência de sucção das partículas, evitando pontos de acúmulo e deposição de partículas no interior do bocal.

Para garantir a estabilidade do bocal durante a varredura do laser e assim o controle preciso da área de amostragem, propõe-se três pontos de contato entre o bocal e a peça ablacionada (pontos de ancoragem), distribuídos simetricamente na extremidade do bocal, conforme Figura 8.

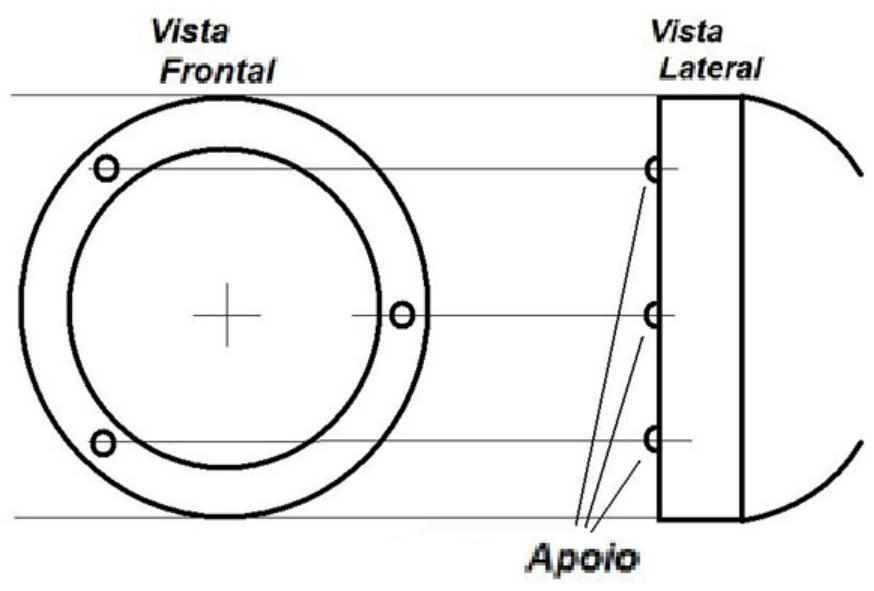

Figura 8 - Apoios do bocal da sonda [Fonte Própria] 
Os pontos de ancoragem também têm a função de impor uma distância fixa entre o bocal da sonda e a superfície da peça amostrada. Esta distância é um dos parâmetros de projeto da sonda discutidos no capítulo de dimensionamento do escoamento. 


\section{DIMENSIONAMENTO DO ESCOAMENTO}

Um esquema de todo o escoamento envolvido no sistema de sucção e filtragem da sonda pode ser observado na Figura 9, na qual os números indicam os canais de escoamento e as letras indicam os eventos localizados de perda de carga:

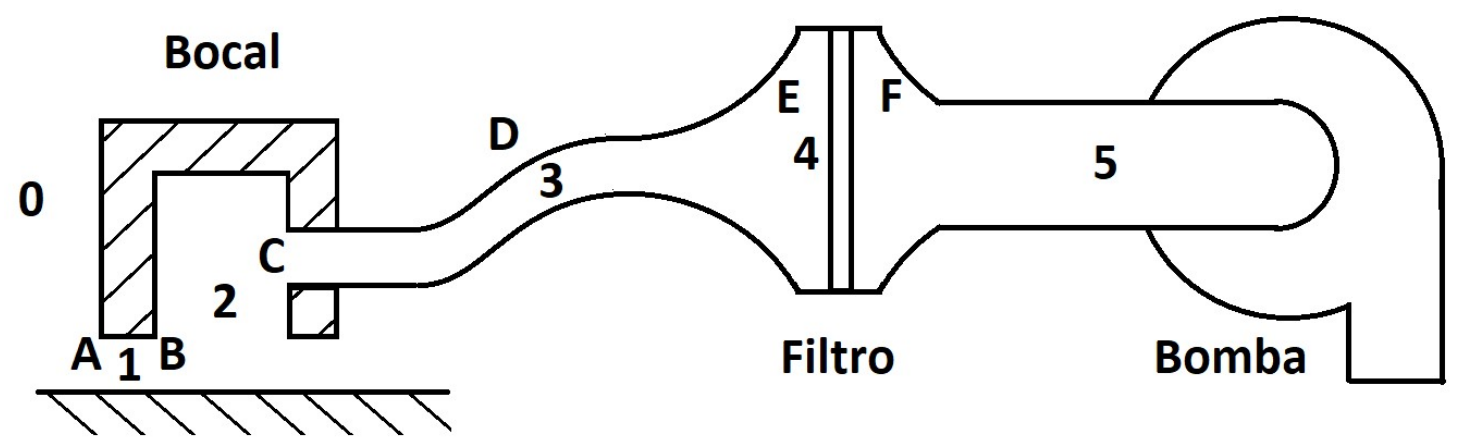

Figura 9 - Esquema do escoamento [Fonte Própria]

Canais:

0 - Meio externo;

1 - Fresta entre o bocal da sonda e a peça;

2 - Canal no interior do bocal;

3 - Tubo conector entre filtro e bocal;

4 - Escoamento imediatamente antes de colidir com filtro;

5 - Duto flexível conector entre filtro e bomba;

Eventos localizados de perda de carga:

A - Entrada de reservatório infinito com canto vivo;

B - Expansão repentina;

A-B - Contração gradual;

C - Contração repentina;

D - Possível curva no tubo;

E - Expansão cônica;

F - Contração Cônica;

E-F - Passagem pelo filtro HEPA; 
O meio fluido em todo escoamento é o ar, com partículas em suspensão entre os canais 2 e 4 . O número de Mach ao longo de todo escoamento nunca será maior que 0,06 e portanto o meio fluido poderá ser tratado matematicamente como incompressível.

\subsection{Velocidades Médias do Escoamento no Circuito}

A velocidade média $(V)$ de um escoamento pode ser calculada como a razão entre a vazão $(Q)$ e a área que o escoamento atravessa $(A)$.

$$
V=\frac{Q}{A}
$$

O valor da velocidade média não dá o valor da velocidade real em um dado ponto do escoamento, porém devido ao comportamento turbulento esperado, sabe-se que praticamente todo escoamento terá um valor ligeiramente acima da velocidade média, exceto uma pequena região muito próxima das paredes do duto (camada limite). Portanto, pode-se dizer que a velocidade média é bastante representativa para o escoamento.

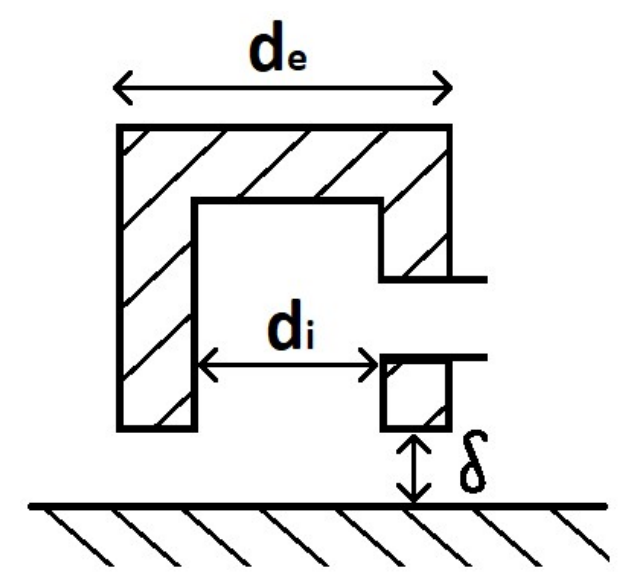

Figura 10 - Parâmetros do Bocal [Fonte Própria]

Assume-se $d_{e}, d_{i}$ e $\delta$ conforme Figura 10; Assume-se $d_{3}$ como o diâmetro do canal 3 , que conecta o bocal ao filtro; Assume-se $d_{f}$ como o diâmetro do filtro; Assume-se $d_{5}$ como o diâmetro do canal 5 . 
Assim, obtém-se a Tabela 4:

Tabela 4 - Fórmula para cálculo de área e velocidades médias [Fonte Própria]

\begin{tabular}{|c|c|c|}
\hline Canal & Área do escoamento & Velocidade Média \\
\hline Canal 1 - Entrada & $A=\delta \pi d_{e}$ & $V=\frac{Q}{\delta \pi d_{e}}$ \\
\hline 1 - Saída & $A=\delta \pi d_{i}$ & $V=\frac{Q}{\delta \pi d_{i}}$ \\
\hline 2 & $A=\pi \frac{d_{i}^{2}}{4}$ & $V=\frac{4 Q}{\pi d_{i}^{2}}$ \\
\hline 3 & $A=\pi \frac{d_{3}^{2}}{4}$ & $V=\frac{4 Q}{\pi d_{3}^{2}}$ \\
\hline 4 & $A=\pi \frac{d_{f}^{2}}{4}$ & $V=\frac{4 Q}{\pi d_{f}^{2}}$ \\
\hline 5 & $A=\pi \frac{d_{5}^{2}}{4}$ & $V=\frac{4 Q}{\pi d_{5}^{2}}$ \\
\hline
\end{tabular}

A princípio, o único valor fixo entre estas variáveis é o diâmetro do filtro $d_{f}$, uma vez que se pretende utilizar para a sonda os filtros HEPA comercialmente vendidos com o diâmetro $d_{f}=50,8 \mathrm{~mm}$. Há outros tamanhos de filtro comercializados, porém este específico está em sintonia com as dimensões finais da sonda e com os métodos de análise rádioquímicos da amostra final.

\subsection{Fluidodinâmica de Sistemas Particulados}

O objetivo do sistema de sucção é arrastar todo o material ejetado na ablação pelo escoamento até o encontro com o filtro, impedindo pontos de sedimentação. Para isso, a velocidade do escoamento do fluido deve ser maior que a velocidade terminal das partículas [34].

O modelo matemático para determinação da velocidade terminal das partículas se inicia considerando a presença de uma única partícula isolada imersa em um escoamento sem extremidades geométricas. Após sua apuração apresentam-se fatores de correção que consideram a presença de outras 
partículas imersas (efeito da concentração) e de paredes que limitam o escoamento (efeito da parede).

\subsubsection{Efeito de Concentração e de Parede no Escoamento Particulado}

- Efeito da concentração na velocidade terminal:

$$
\frac{V_{t}}{V_{\infty}}=\frac{1}{1+2,5 c_{v}}
$$

$V_{t}-$ Velocidade terminal real da partícula;

$V_{\infty}$ - Velocidade terminal da partícula isolada;

$c_{v}$ - Concentração volumétrica do material particulado;

No caso da sonda, a concentração volumétrica do particulado no escoamento é desprezível devido ao grande volume de ar movido a fim de transportar um volume tão pequeno de material ejetado na ablação. Assim,

$$
c_{v}=\sim 0
$$

Logo,

$$
V_{t}=V_{\infty}
$$

- Efeito da parede na velocidade terminal:

$$
\frac{V_{t}}{V_{\infty}}=k_{p}
$$

$V_{t}-$ Velocidade terminal real da partícula;

$V_{\infty}$ - Velocidade terminal da partícula num escoamento sem parede;

O fator de correção $k_{p}$ é função de uma série de parâmetros, entre eles a razão entre o diâmetro do tubo do escoamento $\left(D_{t}\right)$ e o diâmetro da 
partícula $\left(D_{p}\right)$. No caso da sonda, em qualquer região do escoamento o diâmetro do tubo será muito maior que o diâmetro das partículas de tal forma que

$$
\frac{D_{p}}{D_{t}}=\sim 0
$$

Assim,

$$
\begin{array}{r}
k_{p}=1 \\
V_{t}=V_{\infty}
\end{array}
$$

Em suma, devido às condições de operação da sonda, tanto o efeito da parede quanto o efeito da concentração podem ser desprezados.

\subsubsection{Cálculo do Arraste de Partículas no Escoamento}

A presente seção se dedica a indicar o procedimento em que é possível calcular a velocidade terminal de partículas em um fluido. Uma vez que no presente trabalho a vazão é limitada ao máximo suportado pelo filtro sem perder confiabilidade, este procedimento será utilizado inversamente, ou seja, partindo de valores conhecidos de velocidade do escoamento, poderemos calcular quais são as características do particulado que serão confiavelmente arrastados.

Hipóteses:

Material do particulado é aço;

Esfericidade do particulado $\phi<0,80$;

Efeito de parede e de concentração desprezíveis;

Dados:

Densidade do ar: $\quad \rho_{a r}=1,205 \mathrm{~kg} / \mathrm{m}^{3}$

Viscosidade do ar: $\quad \mu_{a r}=18,20 * 10^{-6} \mathrm{Ns} / \mathrm{m}^{2}$

Densidade do aço: $\quad \rho_{\text {aço }}=7860 \mathrm{~kg} / \mathrm{m}^{3}$

Aceleração da gravidade: $\quad g=9,81 \mathrm{~m} / \mathrm{s}^{2}$ 
Outras variáveis:

Granulometria ou diâmetro de partícula: $D_{p}$

Coeficiente de arrasto:

$c_{d}$

Velocidade do escoamento:

V

Cálculo dos adimensionais $k_{1}$ e $k_{2}$

$$
\begin{gathered}
k_{1}=0,843 \log \left(\frac{\phi}{0,065}\right) \\
k_{2}=5,31-4,88 \phi
\end{gathered}
$$

Cálculo do adimensional $c_{d} R e^{2}$

$$
c_{d} R e^{2}=\frac{4}{3} * \frac{\rho_{a r}\left(\rho_{a c ̧ o}-\rho_{a r}\right) g D_{p}^{3}}{\mu_{a r}^{2}}
$$

Cálculo do número de Reynolds $R e$, em função de $k_{1}, k_{2}$ e $c_{d} R e^{2}$

$$
\operatorname{Re}=\left[\left(\frac{k_{1} c_{d} R e^{2}}{24}\right)^{-1,2}+\left(\frac{c_{d} R e^{2}}{k_{2}}\right)^{-\frac{1,2}{2}}\right]^{-\frac{1}{1,2}}
$$

Uma vez obtido o número de Reynolds, pode-se calcular a velocidade do escoamento por meio da fórmula tradicional do número de Reynolds para um escoamento ao redor de uma esfera, a seguir:

$$
R e=\frac{D_{p} V \rho_{a r}}{\mu_{a r}}
$$

O valor obtido da velocidade $V$ é a velocidade no ponto mais crítico do escoamento, do ponto de vista do carregamento de partículas. No sistema de sucção da sonda, este ponto é o canal 2, por apresentar a menor velocidade 
do escoamento e potencialmente ter de carregar o particulado contra a gravidade.

Após uma série de iterações readequando os parâmetros da sonda, visando maximizar a eficiência do arraste de particulado e a eficiência do filtro, chegou-se a seguinte série de parâmetros.

Parâmetros da sonda:

$$
\begin{gathered}
d_{i}=45 \mathrm{~mm} ; d_{e}=65 \mathrm{~mm} ; \delta=3 \mathrm{~mm} ; d_{3}=20 \mathrm{~mm} ; \\
d_{f}=50,8 \mathrm{~mm} ; d_{5}=30 \mathrm{~mm}
\end{gathered}
$$

A vazão do escoamento $Q$ foi calculada respeitando o máximo recomendado pelo fabricante do filtro HEPA, para garantir a sua confiabilidade. O valor desta vazão máxima é 4,0 CFM (cubic feet per minute).

$$
Q=4,0 C F M=0,00189 \mathrm{~m}^{3} / \mathrm{s}
$$

Sendo $Q$ a vazão válida para todo o escoamento.

Aplicando as equações de arraste de particulado, chega-se a conclusão que para este valor de vazão, o escoamento será eficiente para carregar partículas de diâmetro até $D_{p}=94 \mu \mathrm{m}$. Este tamanho de partícula passa a ser meta do processo de ablação, que deve ejetar partículas menores que este diâmetro.

\subsection{Perdas de Carga e Potência da Bomba}

Em um escoamento, a partir do princípio de Bernoulli define-se carga $H$ em um ponto $i$ qualquer conforme a seguinte somatória:

$$
H_{i}=\frac{V_{i}^{2}}{2 g}+\frac{p_{i}}{\gamma}+z_{i}
$$

Onde,

$V_{i}$ - velocidade no ponto i, ou velocidade média em uma seção com escoamento turbulento;

$g$ - aceleração da gravidade;

$p_{i}$ - pressão relativa no ponto i;

$\gamma$ - peso específico do fluido;

$z_{i}$ - altura do ponto i; 
Esta definição de carga é útil pois se sabe que entre dois pontos quaisquer $i$ e $j$ do escoamento a diferença de carga $\Delta H_{i-j}$ é dada por:

$$
\Delta H_{i-j}=h_{f i-j}+\sum h_{s i-j}
$$

Onde,

$h_{f i-j}$ - perda de carga distribuída entre i e j;

$h_{s i-j}$ - perdas de carga localizadas entre i e j.

$\mathrm{E}$,

$$
\begin{gathered}
h_{f}=\frac{f L V^{2}}{D_{h} 2 g} \\
h_{s}=\frac{k V^{2}}{2 g}
\end{gathered}
$$

sendo,

$f$ - coeficiente de atrito obtido pelo Diagrama de Moody (Figura 11);

$L$ - Comprimento do duto;

$D_{h}$ - Diâmetro hidráulico do duto;

$k$ - coeficiente de perda de carga localizada.

O valor do coeficiente de atrito $f$ deve ser obtido do diagrama de Moody em função dos parâmetros $\varepsilon / D$ e número de Reynolds $R e$ para escoamento em dutos, sendo:

$\varepsilon$ - Rugosidade do duto;

D - Diâmetro do duto. 


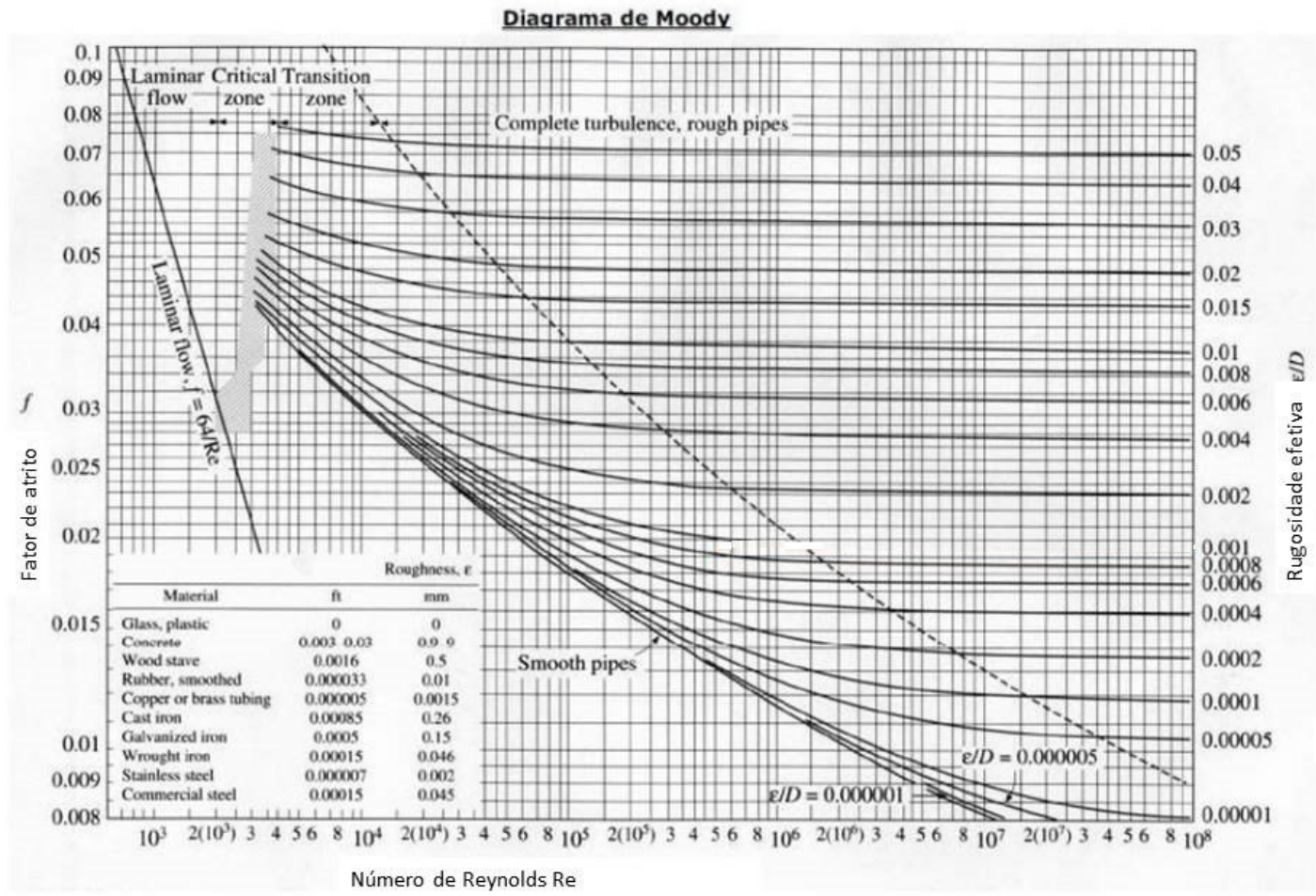

Figura 11 - Diagrama de Moody [35]

Logo,

Na tomada de ar

$$
H_{0}=\frac{V_{0}^{2}}{2 g}+\frac{p_{0}}{\gamma}+z_{0}=0+0+0=0
$$

Antes da bomba

$$
H_{5}=\frac{V_{5}^{2}}{2 g}+\frac{p_{5}}{\gamma}+z_{5}=\frac{2,7^{2}}{2 * 9,8}+\frac{p_{5}}{11,82}+0=0,37+\frac{p_{5}}{11,82}
$$

Assim,

$$
H_{0}-H_{5}=h_{f 3}+h_{f 5}+h_{S A}+h_{S B}+h_{S A B}+h_{S C}+h_{S E}+h_{S F}+h_{S E F}
$$

Especificamente, para o cálculo da perda de carga no filtro $h_{S E F}$, existe o diagrama da Figura 12 disponibilizado pelo fabricante, indicado pela curva FP47M. 
Typical Pressure Drop Vs Flow Rate Values for $47 \mathrm{~mm}$ Diameter Filter Paper

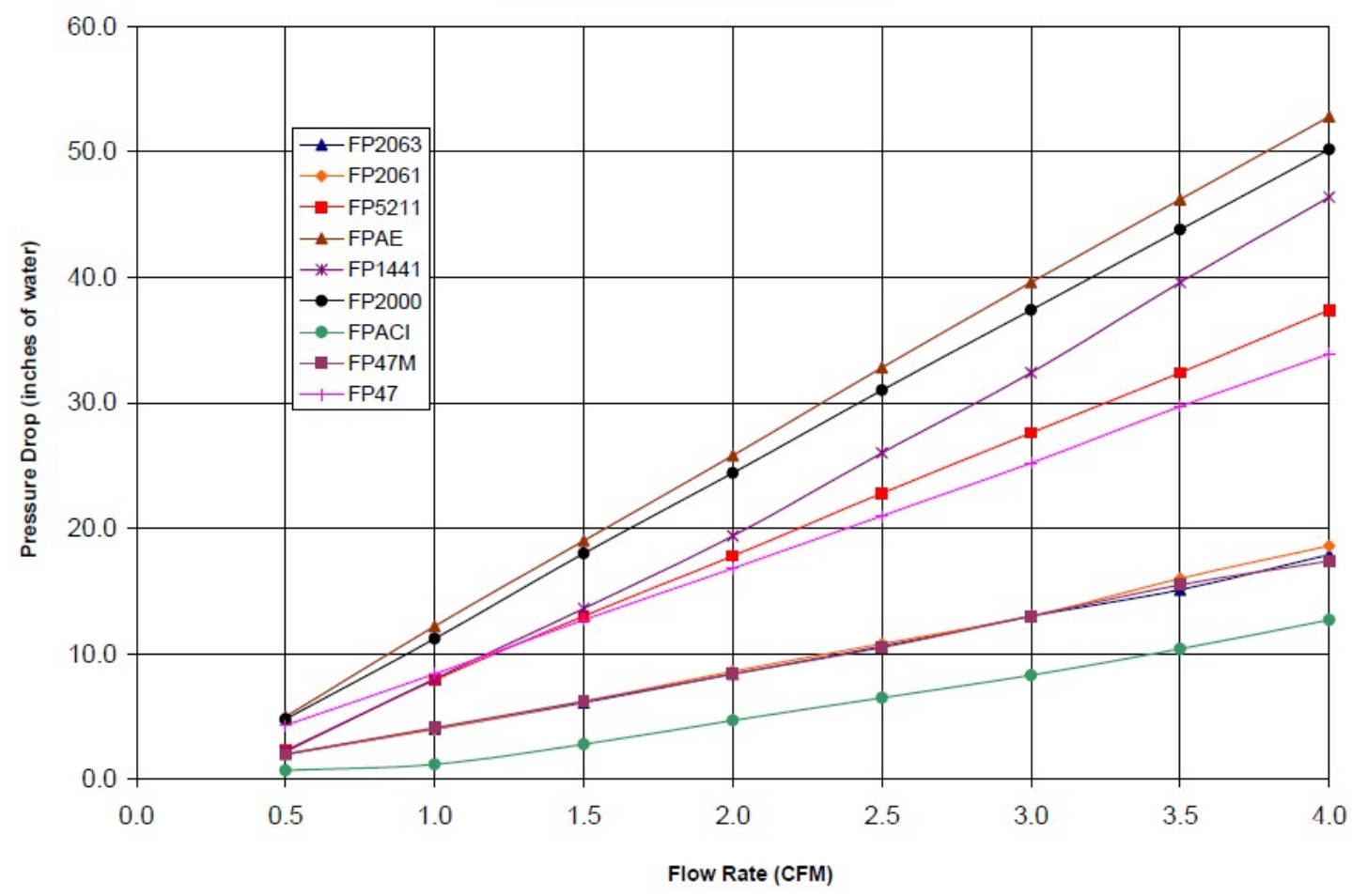

Figura 12 - Perda de carga no filtro FP47M

Para a vazão do sistema $Q=0,00189 \mathrm{~m}^{3} / \mathrm{s}=4 \mathrm{cfm}$, obtém-se o valor de queda de pressão de $p=17$ inches of water. Em termos de perda de carga para o escoamento da sonda, pode ser traduzida como

$$
h=\frac{0,0254 p 1000}{1,205}=358,3 \mathrm{~m}
$$

Para o restante das perdas de carga localizadas, os valores de $k$ encontrados podem ser observados na Tabela 5.

Tabela 5 - Perda de carga localizada [Fonte Própria]

\begin{tabular}{|c|l|c|c|c|}
\hline \multicolumn{5}{|c|}{ Perda de Carga Localizada } \\
\hline Evento & Tipo de evento & $\mathrm{k}[35]$ & $\mathrm{V}(\mathrm{m} / \mathrm{s})$ & $\mathrm{h} / \mathrm{m})$ \\
\hline A & Canto vivo de reservatório infinito & 0,5 & 3,081 & 0,2421 \\
\hline B & Expansão repentina & 0,8 & 4,450 & 0,8083 \\
\hline A-B & Contração gradual & 0,02 & 3,081 & 0,0097 \\
\hline C & Contração repentina & 0,35 & 1,187 & 0,0251 \\
\hline E & Expansão Cônica & 1,0 & 6,007 & 1,8413 \\
\hline F & Contração Cônica & 0,07 & 0,931 & 0,0031 \\
\hline E-F & Filtro & não se aplica & 0,931 & 358,34 \\
\hline Somatória & & & 361,2696 \\
\hline
\end{tabular}


Para as perdas de carga distribuídas, os únicos canais relevantes para este tipo de cálculo são o 3 e 5, devido suas extensões. Com o uso do diagrama de Moody, pode-se encontrar o valor do fator de atrito $f$ em função da rugosidade e diâmetro do duto ( $\varepsilon$ e $D$, respectivamente) e do número de Reynolds Re para escoamento em dutos. As perdas distribuídas e seus parâmetros estão explicitadas na Tabela 6:

Tabela 6 - Perdas de carga distribuídas [Fonte Própria]

\begin{tabular}{|c|c|c|c|c|c|c|c|}
\hline \multicolumn{7}{|c|}{ Perda de Carga Distribuída } \\
\hline Canal & $\operatorname{Re}$ & $\varepsilon(\mathrm{m})$ & $\varepsilon / \mathrm{D}$ & $\mathrm{f}$ & $\mathrm{L}(\mathrm{m})$ & $\mathrm{V}(\mathrm{m} / \mathrm{s})$ & $\mathrm{hf}(\mathrm{m})$ \\
\hline 3 & 7954,94 & 0,000046 & 0,0023 & 0,026 & 0,1 & 6,007 & 0,2391 \\
\hline 5 & 5303,29 & 0,0015 & 0,05 & 0,072 & 2,0 & 2,670 & 1,7441 \\
\hline Somatória
\end{tabular}

Como esperado, o filtro oferece a maior resistência ao fluxo, sendo responsável por $98 \%$ da perda de carga total.

Como

$$
H_{0}-H_{5}=h_{f 3}+h_{f 5}+h_{S A}+h_{S B}+h_{s A B}+h_{S C}+h_{S E}+h_{S F}+h_{s E F}
$$

Então

$$
0-\left(0,37+\frac{p_{5}}{11,82}\right)=363,25
$$

Isolando-se o $p_{5}$, obtém

$$
p_{5}=-4297,99 \mathrm{~Pa}
$$

O valor negativo de $p_{5}$ é coerente e indica que a pressão do escoamento imediatamente antes da bomba é menor que a pressão atmosférica, como esperado. Esta queda de pressão é promovida pela bomba e seu valor será utilizado para calcular a potência necessária da bomba.

$$
H_{5}=0,37+\frac{p_{5}}{11,82}=-363,25 \mathrm{~m}
$$

Considerando que após a bomba, o escoamento volta para o meio externo, chamado já de ponto 0 , cuja carga já calculada é nula.

Assim, a carga da bomba $H_{B}$ é dada como

$$
H_{B}=H_{0}-H_{5}=363,25 \mathrm{~m}
$$

$\mathrm{E}$ a potência útil da bomba pela fórmula:

$$
N_{\text {útil }}=\gamma Q H_{B}
$$


Onde,

$N_{\text {útil }}$ - Potência útil da bomba (W);

$\gamma$ - peso específico do ar $\left(\mathrm{N} / \mathrm{m}^{3}\right)$;

$Q$ - Vazão do escoamento $\left(\mathrm{m}^{3} / \mathrm{s}\right)$.

Para os parâmetros da sonda, a potência útil da bomba é

$$
N_{\text {útil }}=11,82 * 0,001888 * 363,25=8,11 \mathrm{~W}
$$




\section{RESULTADOS}

Com base em todas estas considerações apresentadas até este ponto do trabalho, pôde-se projetar a sonda de captura de particulado e suas peças. O desenho de conjunto da sonda está disponível no APÊNDICE I e os desenhos de fabricação das peças componentes se encontram no APÊNDICE II.

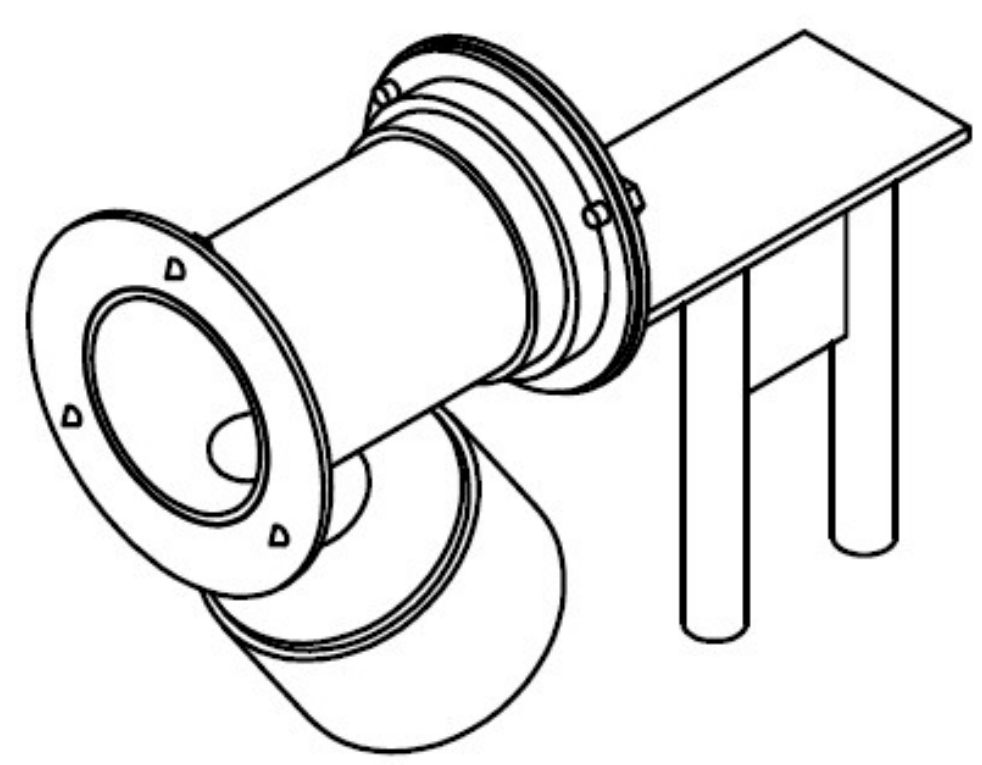

Figura 13 - Vista Isométrica da sonda [Fonte Própria]

Na Figura 13, a plataforma à direita está destinada a fixação dos aparelhos ópticos necessários para realizar o foco e a varredura do feixe de laser. O design desta plataforma não está finalizado, uma vez que a equipe responsável pelo laser indicará furos e mudanças de dimensões necessárias.

Não estão mostrados na figura a fibra óptica do laser e os cabos de controle eletrônico dos aparelhos ópticos, ambos entrando por trás da plataforma, e o duto de ar flexível saindo por baixo pelo adaptador do filtro de ar. O duto, a fibra ótica e os cabos devem se juntar logo atrás da sonda, formando um único chicote ligando a sonda a um carrinho de suporte, que deverá conter o aparelho laser, a bomba de ar e o controlador dos aparelhos ópticos. 
A empunhadura abaixo da plataforma de aparelhagem óptica se destina ao melhor manuseio da sonda pelo operador, trazendo a possibilidade de alojar um botão de início da ablação e varredura.

Conforme pode ser observado no APÊNDICE I, o material base usado para a construção da sonda é o aço 1020. Esta liga foi optada pelo seu apelo econômico e por sua alta usinabilidade. Além disto, é recomendado o tratamento superficial de cementação na face interna do bocal com o intuito de aumentar sua dureza e resistência a abrasão. Outra opção de material é o aço inoxidável, que oferece vantagem sobre o aço 1020 de maior resistência a corrosão.

\subsection{Disponibilidade de Peças}

Visando a facilidade de produção da sonda, o seu projeto foi desenvolvido visando à utilização de peças já existentes de mercado. A escolha dos produtos comerciais foi feita com base na coerência de seus dados técnicos com os parâmetros esperados pelo projeto, bem como a conveniência do uso de produtos já conhecidos e utilizados em outros projetos do IPEN.

O filtro (Figura 14) escolhido para sonda é o FP2.0M da companhia HI-Q Environmental Products Company Inc. Este produto é composto por microfibras de vidro borossilicato e um aglutinante de resina acrílica. Seu diâmetro de 2 polegadas $(50,8 \mathrm{~mm})$ é conveniente para o tamanho do que se esperava ser a sonda. Sua pequena massa $m_{f}=0,158 \mathrm{~g}$ (valor utilizado no cálculo da área mínima de amostragem) proporciona maior sensibilidade de detecção de radionuclídeos pelos laboratórios do IPEN. 


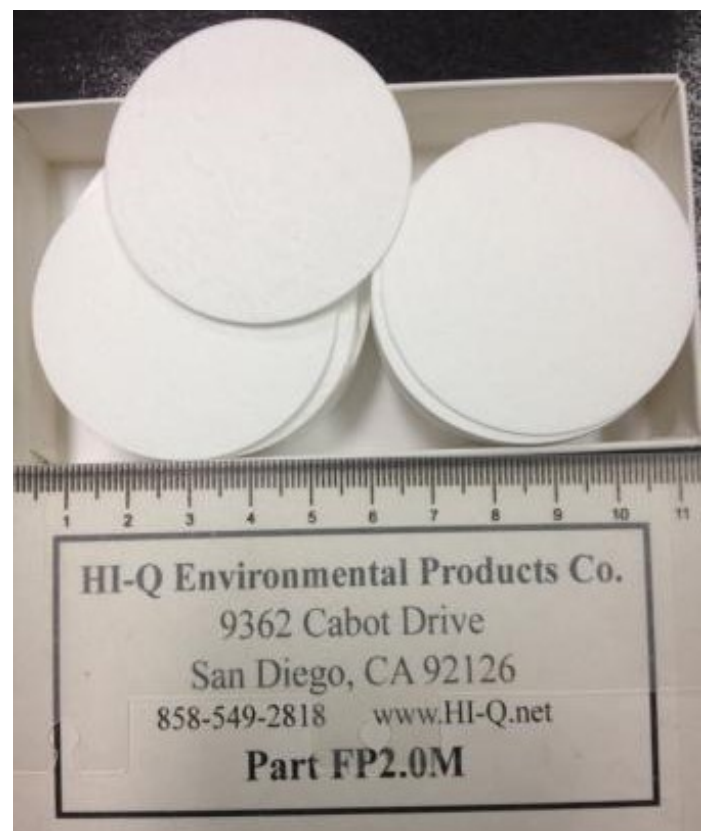

Figura 14 - Filtro FP2.0M [Fonte Própria]

A peça que mantém o disco do filtro fixo é o suporte de engate rápido de filtro HEPA em disco, mostrado na Figura 15.

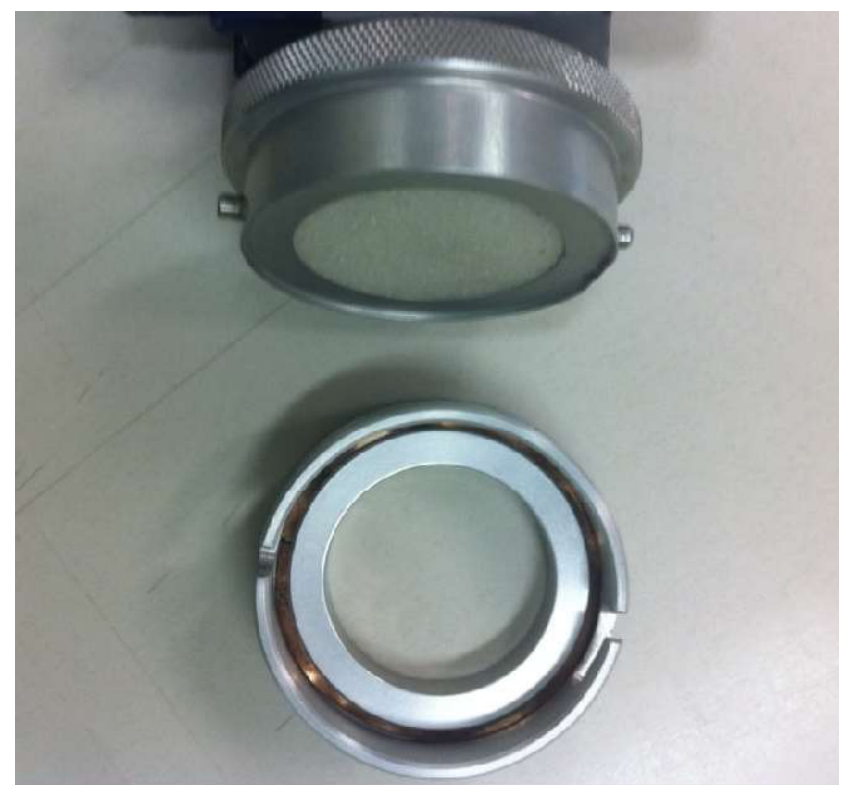

Figura 15 - Suporte de engate rápido do filtro HEPA em disco [Fonte Própria]

Na figura, a peça abaixo fica à montante no escoamento e a outra peça, a maior, fica à jusante, ou seja, acoplada no duto flexível que leva à bomba. O sistema é facilmente acoplado e desacoplado por meio de uma torção relativa entre as peças, o que é bastante adequado para a sonda. A 
troca de disco HEPA será feita com considerável freqüência (uma vez para cada ciclo de ablação) e o equipamento precisa ser prático na colheita de amostras.

A bomba de ar será adaptada de um aspirador de pó Black and Decker AP2000, que pode ser visto na Figura 16.

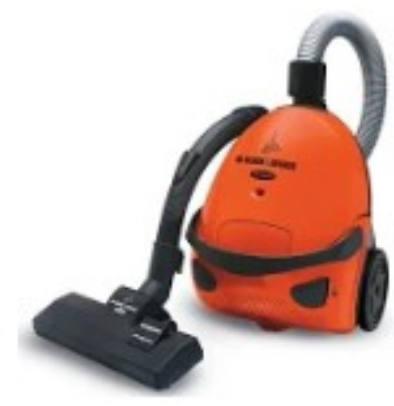

Figura 16 - Aspirador de pó Black and Decker AP2000

Este produto, de massa $5,9 \mathrm{~kg}$, oferece uma potência consumida de $1400 \mathrm{~W}$, indicando que alcançará a potência útil necessária ao funcionamento da bomba. $O$ filtro interno do equipamento é um filtro HEPA, e servirá aos propósitos de segurança do operador da sonda e do recinto onde será aplicada a sonda (muito embora não dispensar o uso de equipamento de proteção individual de filtragem da respiração pelo operário e nem sistema de filtragem do ar do recinto).

A princípio, a potência útil gerada pelo aspirador de pó no escoamento excederia a potência requerida pelo projeto, de apenas $8,11 \mathrm{~W}$. Esta diferença deverá ser compensada pelo uso de redutores de pressão. $O$ redutor de pressão é um anteparo com apenas um orifício central, por onde o fluxo é obrigado a passar. 


\section{DISCUSSÃO DOS RESULTADOS}

\subsection{Instruções de Operação e Radioproteção}

O uso da sonda de amostragem é simples, contendo poucos passos, mas deve ser seguido integralmente para garantir tanto a precisão da amostragem como a segurança do operador. As instruções de segurança no presente trabalho não dispensam as instruções obrigatórias tradicionais da indústria nuclear pertinentes, apresentadas por órgãos regulatórios.

O operador da sonda deve aproximar o equipamento da superfície da peça que precisa ser analisada. A sonda deve ser apoiada contra a peça utilizando-se os três pontos de apoio do bocal. Sem mexer na posição da sonda até o final da sucção, o operador deve acionar o botão de início da amostragem, que deve automaticamente acionar primeiramente a sucção e um segundo após, a ablação. Enquanto o sistema de controle direcional do laser faz a varredura da área de amostragem, o sistema de sucção carrega os aerossóis para o filtro. Terminada a ablação, o sistema de sucção continua ligado por mais 10 segundos para garantir a sucção das últimas partículas. Desligada a bomba de sucção, o operador pode recolher a sonda e utilizandose do engate rápido do suporte do filtro, deve-se abri-lo para retirada do disco HEPA e sua deposição em invólucro adequado e identificado. Um novo disco pode ser então inserido no suporte, e este pode ser fechado, tornando a sonda já pronta para mais uma colheita de amostra. O invólucro deve ser enviado para o laboratório para que o disco contaminado possa ser analisado por métodos radioquímicos.

Devem ser observadas as questões relativas à radioproteção do uso do aparelho, especialmente aquelas que se referem à contaminação do usuário da sonda por material radioativo. Deve-se ter em mente que o ambiente em torno da sonda após a ablação poderá conter particulado aerossol radioativo em suspensão no ar.

Embora a função do sistema de sucção da bomba seja a captação do material ejetado na ablação - material este potencialmente radioativo - e sua retenção no filtro HEPA, o operador não pode depender apenas desta 
barreira para não aspirar partículas radioativas. Seja por mau funcionamento do filtro ou até mesmo pela natureza caótica da retenção de partículas num filtro (o que impede uma eficiência perfeita na captação), outros filtros devem estar envolvidos no sistema de segurança.

A Figura 17 é um esquema de como deve ser o sistema de filtragem completo.

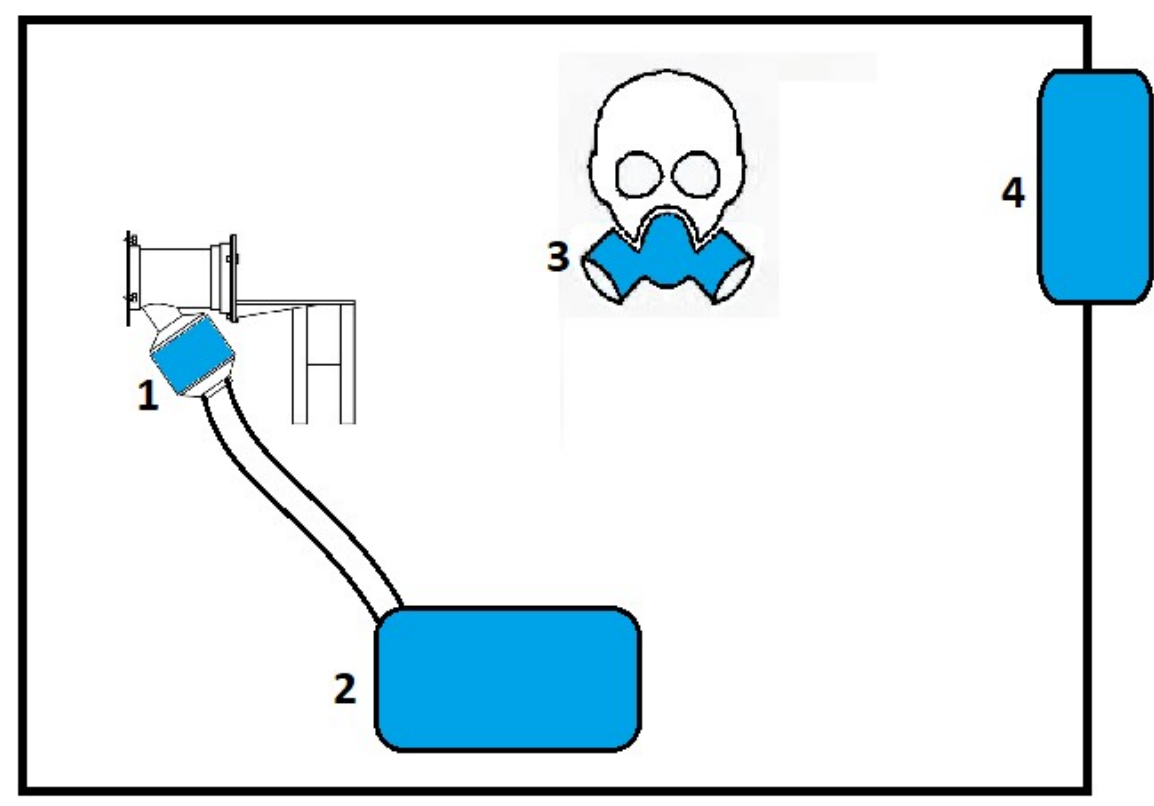

Figura 17 - Sistema de filtragem de radioproteção [Fonte Própria]

Na figura, o item 1 representa o disco HEPA da sonda removível que deve ser encaminhado aos laboratórios para análise radioquímica. Este é o principal filtro e aqui se espera ficarem retidas 99,99\% das partículas. O item 2 representa a bomba de ar da sonda (aspirador de pó adaptado) com o seu filtro HEPA interno, para captar partículas que atravessaram o filtro principal.

Finalmente, partículas podem chegar ao ar do recinto por dois meios, evasão pela fresta entre o bocal da sonda e a peça ablacionada ou atravessando os filtros 1 e 2. Assim, o operador deve utilizar máscara com filtro para respiração (item 3 na figura), juntamente com vestimenta selada, e o próprio recinto deve ter seu ar reciclado por um sistema de filtragem ambiente (item 4). 
Além destas medidas, o operador deve passar por exames regulares de excreta (exame de urina) para mensurar e controlar sua contaminação interna, conforme prática adotada pela indústria radionuclear.

\subsection{Instruções para Teste de Bancada}

\subsubsection{Teste sem Ablação}

Inicialmente, a bomba de ar deve ser adaptada para que a vazão do escoamento atinja o valor de projeto. Isto pode ser feito por meio do acoplamento do redutor de pressão na entrada da bomba. O tamanho ideal do orifício central do redutor pode ser obtido por testes com o auxílio de um Tubo de Pitot para medição da velocidade de escoamento. Estes testes devem ser feitos com o equipamento todo montado, exceto o sistema óptico do laser (ainda não necessário nesta fase), simulando uma aplicação real contendo já o disco HEPA dentro do suporte do filtro e inclusive uma superfície apoiada no bocal da sonda simulando a peça ablacionada.Definidas as dimensões do redutor de pressão, o Tubo de Pitot pode ser retirado.

\subsubsection{Teste com Ablação de Peça não Contaminada}

Neste teste, o equipamento deve ser montado com o sistema de ablação com laser operante, mesmo que o sistema de varredura da área de amostragem ainda não esteja implementado. Uma placa de aço não contaminada deve ser utilizada simulando a peça contaminada a ser amostrada. Previamente, tanto a placa de aço quanto o disco HEPA devem ter suas massas apuradas por meio de uma balança de precisão. A sonda deve ser acionada para iniciar a sucção e seqüente ablação. Findo o teste, novamente com o auxílio da balança de precisão, deve ser analisada a massa perdida da placa de aço e a massa acrescentada no filtro HEPA para se estimar a eficiência do sistema de sucção e filtragem. Nesta fase, a inspeção 
visual também deve ser feita durante a ablação para identificar possíveis partículas evasoras.

\subsubsection{Teste com Ablação de Peça Contaminada Conhecida}

Este teste compreende a avaliação final que poderá validar todo o equipamento de amostragem - tanto o sistema de sucção e filtragem como o sistema de ablação. É, portanto, necessário que todos os sistemas estejam já implementados na sonda.

Neste teste, uma peça contaminada superficialmente será amostrada. O inventário radioisotópico desta peça, no entanto, deve ser conhecido, seja por métodos tradicionais de levantamento de inventário, seja pelo controle da contaminação proposital da peça.

Todas as instruções de operação e segurança da sonda devem ser seguidas, e a amostra deve ser encaminhada para laboratório para medição. 0 resultado da análise laboratorial deve ser então comparado com o valor esperado devido o conhecimento prévio do inventário radioisotópico da peça.

\subsubsection{Teste de Consistência de Resultado a Longo Prazo}

Um possível fenômeno de contaminação dos dutos internos da sonda pode ocorrer conforme o uso persistente da sonda, especialmente em peças com elevada concentração de radionuclídeos. Apesar de o projeto da sonda ser pensado de tal forma a evitar sedimentação de material ejetado na sonda, o efeito cumulativo de diversos usos da sonda pode gerar uma concentração interna de material radioativo suficiente para interferir nos resultados de inventário radioisotópico. Com este teste, pretende-se estimar o efeito desta contaminação interna e sua interferência nos resultados da amostra.

Após a validação da sonda pelo "Teste com ablação de Peça Contaminada Conhecida", a sonda poderá já ser utilizada para seu uso final, 
porém ainda atravessando um período de cautela, em que os resultados do inventário radioisotópico não estarão livres de suspeita. Deve-se, durante este período de cautela, fazer várias amostragens, especialmente em peças potencialmente muito contaminadas.

Para finalizar este período de cautela, deve-se realizar este teste de consistência de resultados a longo prazo, em que a sonda completa deve colher amostras para análise laboratorial de uma peça de aço não contaminada. O resultado do laboratório deve ser um inventário radioisotópico nulo, validando assim a consistência da sonda a longo prazo. Caso seja detectada a presença de algum radionuclídeo pelo laboratório, se provará que amostragens prévias interferem no resultado de amostragens futuras. Um estudo pode ser feito neste caso para determinar possíveis soluções para este problema, como substituição regular de peças da sonda ou algum algoritmo computacional capaz de compensar o rastro de amostragens anteriores.

\subsection{Materiais Diversos da Peça Ablacionada e Eficiência da Sucção}

Uma das hipóteses para o cálculo do arraste das partículas foi que o material da peça ablacionada é o aço. Esta hipótese é adotada para se considerar sua densidade e assim proceder com os cálculos de arraste de partículas. Nesta seção, se observará o efeito da densidade no arraste para que se possa estimar o limite de tamanho de partícula arrastada para diferentes materiais metálicos.

Adotando novos valores de densidade e refazendo o cálculo de fluidodinâmica de sistemas particulados para cada valor, obtém-se o seguinte padrão, mostrados em tabela e gráfico na Figura 18. 


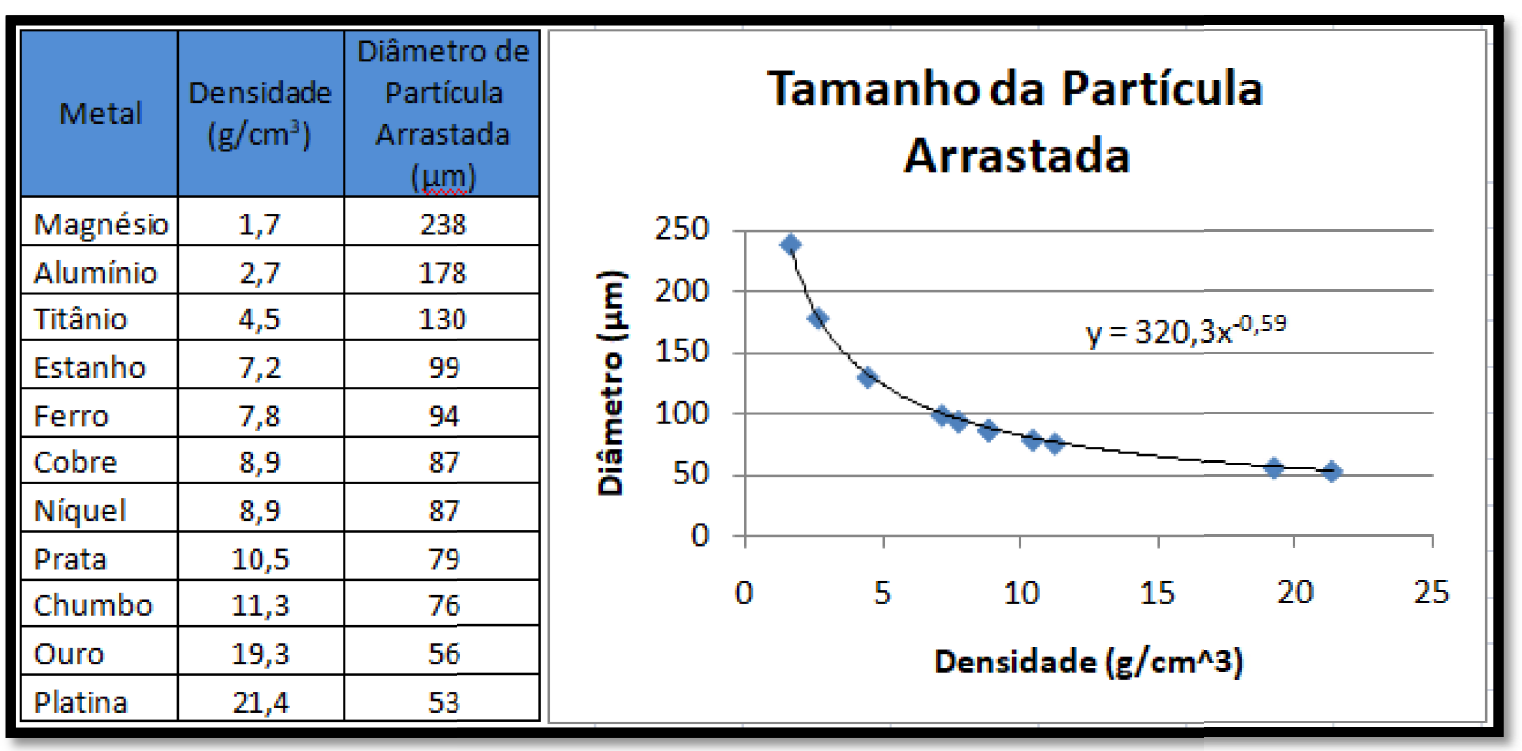

Figura 18 - Tamanho de partícula arrastada em função da densidade [Fonte Própria]

Como pode ser observado pelo gráfico, a curva tem formato típico de função potência e de fato pode ser aproximada com elevada fidelidade (coeficiente de determinação $R^{2}=0,999$ ) pela seguinte função:

$$
D_{p}=320,3 \rho^{-0,59}
$$

, com o diâmetro da partícula $D_{p}$ em $\mu \mathrm{m}$ e a densidade $\rho$ do material em $\mathrm{g} / \mathrm{cm}^{3}$.

Outra hipótese adotada inicialmente no cálculo de arraste de partículas é que o valor de esfericidade das partículas vale 0,8. A seguir se discorrerá sobre o impacto de diferentes valores de esfericidade no arraste de partícula.

A esfericidade (Ф) é definida como sendo o coeficiente entre a superfície da esfera com o mesmo volume que a partícula e a superfície real, $S_{p}$. [34]

$$
\Phi=\pi D_{p}^{2} / S_{p}
$$

Assim, o valor de esfericidade varia entre zero e um, sendo "um" uma esfera perfeita e valores próximos de zero formatos mais próximos de uma casca.

De uma forma geral, quanto mais próximo de uma esfera, mais a dificuldade de arraste de uma partícula. Testando alguns materiais para valores de esfericidade diferentes, obteve-se o seguinte padrão (Figura 19). 


\begin{tabular}{|c|c|c|c|c|}
\hline \multirow[b]{2}{*}{ Metal } & \multirow{2}{*}{$\begin{array}{c}\text { Densidade } \\
\left(\mathrm{g} / \mathrm{cm}^{\wedge} 3\right)\end{array}$} & \multicolumn{3}{|c|}{ Diâmetro de Partícula Arrastada ( $\mu \mathrm{m})$} \\
\hline & & $\begin{array}{c}\text { Esfericidade }= \\
1,0\end{array}$ & $\begin{array}{c}\text { Esfericidade }= \\
0,8\end{array}$ & $\begin{array}{c}\text { Esfericidade }= \\
0,6\end{array}$ \\
\hline Magnésio & 1,7 & 183 & 238 & 298 \\
\hline Ferro & 7,8 & 80 & 94 & 110 \\
\hline Chumbo & 11,3 & 65 & 76 & 87 \\
\hline Platina & 21,4 & 47 & 53 & 60 \\
\hline
\end{tabular}

\section{Efeito da Esfericidade no Arraste}

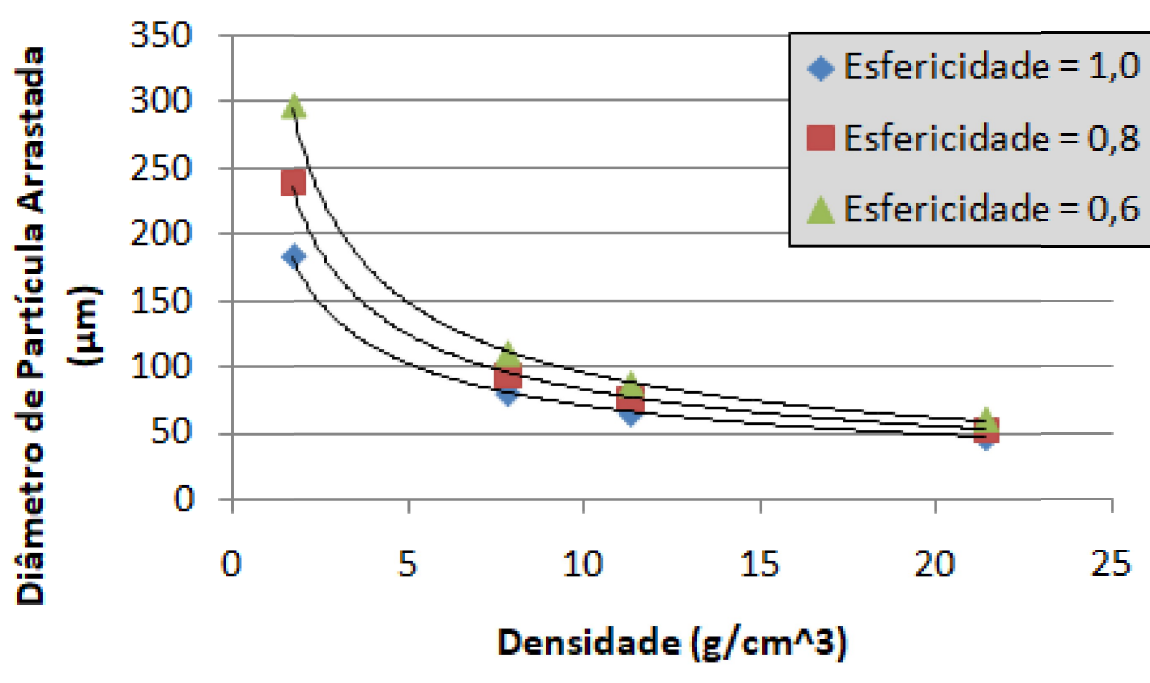

Figura 19 - Impacto da esfericidade no arraste de partículas [Fonte Própria]

Nota-se que o padrão de função potência se mantém, e que materiais de densidade menor são mais sensíveis a variação da esfericidade.

Convém, neste ponto do trabalho, uma rápida discussão a respeito da correlação esperada entre tamanho de partícula e sua esfericidade. Como já observado no capítulo referente às características do material ejetado na ablação, as menores partículas ejetadas são potencialmente formadas pelo processo de condensação dos íons no plasma. Isto justificaria um alto valor de esfericidade da partícula, uma vez observadas as qualidades isotrópicas que envolvem um processo de condensação. Por outro lado, as maiores partículas, que por sua maior massa seriam as de maior dificuldade de arraste no escoamento, são potencialmente formadas pelo processo de despreendimento direto da peça ablacionada. Espera-se deste mecanismo de despreendimento um comportamento mais caótico o que propiciaria partículas assimétricas e com menor valor de esfericidade. Este fenômeno de fato já foi observado nos 
laboratórios de ablação do IPEN, em que partículas grandes em formato de casca foram encontradas. Esta correlação entre tamanho de partícula e esfericidade tem efeito positivo na eficiência do arraste do escoamento, ampliando a faixa de tamanho de partículas efetivamente carregadas.

\subsection{Sensibilidade dos Parâmetros de Projeto}

\subsubsection{O Caso de Particulado não Arrastado}

A eficiência da sonda de amostragem deste trabalho se apóia na hipótese que a meta de tamanho de partícula ejetada na ablação seja exeqüível pela equipe que lida com os aspectos técnicos do laser e da ablação. Caso esta meta não seja possível, um estudo pode ser feito para adequação do projeto de sucção e filtragem da sonda para maximizar sua eficiência.

Para aumentar o arraste na região do escoamento interna do bocal, poder-se-ia sugerir diminuir o diâmetro do bocal, proporcionando maior velocidade do escoamento. Esta alteração poderia ser alcançada de duas formas: diminuindo o afastamento de segurança entre a superfície interna do bocal e a pluma de plasma ; ou diminuindo a própria área de amostragem da peça. A primeira é possível porque o afastamento foi projetado com grande fator de segurança, e traria um ligeiro crescimento da faixa de tamanho de partícula arrastada. A segunda também é possível e traria um grande aumento do diâmetro de partícula arrastada. O problema da área de amostragem incompleta poderia ser contornado desprezando-se a medição do radionuclídeo Níquel-63, que foi o agente limitador da área de amostragem por larga margem (área mínima de amostragem 2,7 vezes maior que a segunda maior área) ou executando amostragens sucessivas de várias áreas usando o mesmo disco HEPA até a somatória das áreas alcançassem o valor da área de amostragem completa.

Infelizmente, embora a possibilidade de diminuição do diâmetro do bocal aumentar a capacidade de arraste em seu escoamento interno, uma outra região passaria a ser a limitante no arraste de partículas: o próprio compartimento do filtro. O diâmetro do disco filtro quase coincide com o 
diâmetro do bocal. Assim, qualquer ganho de arraste no bocal pela diminuição de seu diâmetro não seria também apreciado no compartimento do filtro, trazendo lá possíveis pontos de sedimentação que não seriam absorvidos pelo filtro.

Uma possível solução para este impasse poderia ser a diminuição do diâmetro do filtro para aumentar a velocidade do escoamento em seu compartimento e conseqüente maior arraste - semelhante ao sugerido com o bocal. Entretanto, isto não é possível, pois o elemento da sonda que limitou a vazão foi justamente o filtro, que deve respeitar uma velocidade máxima do escoamento em sua face para manter sua eficiência. Diminuir o tamanho do filtro, ao invés de aumentar a velocidade do escoamento na região, manteria a mesma velocidade de escoamento e ainda diminuiria a vazão de todo o circuito - prejudicando assim o arraste em todos os outros canais.

Fica assim argumentado que a alteração dos diâmetros, seja do bocal, seja do filtro, não seria solução para um possível problema de particulado muito grande gerado na ablação.

A opção mais viável para corrigir este problema seria aumentar a potência útil da sucção, conseqüentemente aumentando a vazão do circuito e as velocidades de escoamento em todos os canais. Isto poderia ser obtido aumentando o diâmetro do orifício central do redutor de pressão acoplado na bomba de ar. O efeito imediato desta alteração é a ultrapassagem do valor de vazão máximo recomendado pelo fabricante do filtro HEPA. Assim, estaria se diminuindo a eficiência da filtragem em prol de uma maior eficiência de sucção. Esta é uma relação de compromisso entre estas duas eficiências, ambas desejáveis, e esta alteração deve ser estudada de tal forma a otimizar a eficiência total (multiplicação das duas eficiências supracitadas).

Esta prática de ultrapassar a vazão máxima recomendada pelo fornecedor de filtro é muito comum na indústria, como informado pelo próprio fornecedor, e pode ser feita com a devida cautela. 


\subsubsection{Impacto de Outros Parâmetros}

O impacto de outros parâmetros do projeto, não relacionados com a questão central do arraste de particulado grande, também pode ser apreciado.

A altura da fresta entre o bocal e a superfície da peça ablacionada pode ser diminuída caso seja observada a evasão de particulado pela fresta durante a ablação e sucção. Esta diminuição, além de diminuir a janela para a evasão, aumenta a velocidade do escoamento entre a peça e o bocal, contribuindo para o arraste de partículas na direção correta. Caso a diminuição interfira negativamente na vazão do escoamento, pode-se compensar aumentado o diâmetro do orifício do redutor de pressão na bomba de ar, trazendo a vazão de volta ao valor de projeto.

Como já observado, caso a lente de vidro esteja perdendo sua integridade devido à sedimentação de particulado, as entradas de ar laterais auxiliares podem ser acrescentadas no bocal próximas à lente para formar uma cortina de ar protetora em frente à lente. O acréscimo destas entradas de ar deve ser feito com cautela, pois acrescentam outra ramificação do escoamento na sonda que vai consumir vazão sem contribuir para o arraste de partícula no interior do bocal, que é um dos canais críticos para o arraste de partícula. 


\section{CONCLUSÕES}

Com o presente trabalho, pôde-se desenvolver o projeto da sonda de captura de material ejetado em ablação para amostragem de superfícies contaminadas radioativamente, que se mostrou exeqüível e com grande potencial para obter amostras confiáveis para levantamento de inventário radioisotópico de peças.

Um estudo sobre as propriedades físicas do material ejetado durante a ablação foi feito para guiar o projeto da sonda de forma a garantir durabilidade, segurança e confiabilidade do equipamento projetado.

A formulação matemática da área mínima de amostragem necessária para detecção de todos os radionuclídeos de interesse em sua concentração limite (normativa) foi desenvolvida na seção ÁREA MíNIMA DE AMOSTRAGEM. Ficou assim calculado que a área de amostragem mínima necessária é de $217,7 \mathrm{~mm}^{2}$.

Em seguida, foi feito o estudo do escoamento segundo a fluidodinâmica de sistemas particulados para conciliar a potência necessária da bomba de ar e as dimensões dos canais com o tamanho de particulado arrastado pelo sistema de sucção. Para filtragem, determinou-se o uso de um disco HEPA encapsulado em um suporte de engate rápido para ágil troca de discos.

Ao longo do projeto, foi observado o quesito prático de se utilizar peças de mercado sempre que conveniente. Assim, a lista de peças comerciais se encontra na seção "Peças de Mercado". Esta escolha facilita a fabricação do produto final e sua reprodutibilidade.

Foi elaborado um guia de operação e segurança para a aplicação da sonda, bem como uma série de testes para avaliação do desempenho da sonda e validação final do equipamento. Caso divergências sejam encontradas, o presente trabalho sugere medidas a serem tomadas para mitigar os problemas surgidos.

As limitações da sonda são explicitadas na seção "Materiais diversos da Peça Ablacionada e Eficiência de Sucção". Basicamente o fator principal que determinará a eficiência da sonda é o tamanho da partícula ejetada, o que torna o envolvimento da equipe responsável pelo laser de suma importância. 
Medidas também são sugeridas caso o tamanho de partícula necessário seja impraticável pela tecnologia da ablação.

Enfim, a sonda apresenta grande potencial para ser um método rápido e altamente confiável de caracterização de contaminantes de peças e conseqüente levantamento de seu inventário radioisotópico. Seu uso poderá agilizar processos de descomissionamento e descarte de peças da indústria nuclear e outros ramos profissionais. 


\section{Referências}

[1] Terremoto, L. A. A. Fundamentos de Tecnologia Nuclear - Reatores. São Paulo - SP: IPEN/CNEN-SP, 2004.

[2] A.J. Potiens Jr.n, J.C. Dellamano, R. Vicente, M.P. Raele, N.U. Wetter, E. Landulfo. Laser decontamination of the radioactive lightning rods. Radiation Physics and Chemistry, 95 (2014): 188-190.

[3] Laser-Based Characterization and Decontamination of Contaminated Facilities. K. H. Leong, B. V. Hunter, J. E. Grace and M. J. Pellin, H. F. Leidich and T. R. Kugler. Argonne national Laboratory, 1996. (ANL/TD/CP_90094)

[4] Russell Ferguson, Martin Edelson, Ho-ming Pang. Laser Ablation System and Method of Decontaminating Surfaces. U.S. Patent No. 5.780.806, July 14,1998

[5] X. Zhou, K. Imasaki, H. Furukawa, C. Yamanaka, S. Nakai. Experimental study on surface decontamination by laser ablation. J. Laser Appl. 14, 13 (2002)

[6] Anton Leontyev. Laser decontamination and cleaning of metal surfaces: modelling and experimental studies. PhD Thesis. Universit'e Paris Sud, 2012.

[7] Fabrice Moggia, Xavier Lecardonnel, Frédérique Damerval. Surface Decontamination Using LASER Ablation Process. WM2012 Conference, February 26 - March 1, 2012, Phoenix, Arizona, USA

[8] International Atomic Energy Agency. Strategy and Methodology for Radioactive Waste Characterization. IAEA, Vienna, 2007 (TECDOC-15237)

[9] International Atomic Energy Agency. Determination and Use of Scaling Factors for Waste Characterization in Nuclear Power Plants. IAEA, Vienna, 2009. (Nuclear Energy Series No. NW-T-1.18)

[10] International Atomic Energy Agency. Classification of Radioactive Waste - General Safety Guide. IAEA, Vienna, 2009. (Safety Standards Series No. GSG-1)

[11] International Atomic Energy Agency. Predisposal Management of Low and Intermediate Level Radioactive Waste - Safety Guide. IAEA, Vienna, 2003 (Safety Standards Series No. WS-G-2)

[12] International Atomic Energy Agency. Storage of Radioactive Waste. IAEA, Vienna, 2006 (Safety Standards Series No. WS-G-6.1)

[13] International Atomic Energy Agency. Disposal of Radioactive Waste Specific Safety Requirements. IAEA, Vienna, 2011 (Safety Standards Series No. SSR-5 
[14] International Atomic Energy Agency. The Management System for the Processing, Handling and Storage of Radioactive Waste - Safety Guide. IAEA, Vienna, 2008 (Safety Standards Series No. GS-G-3.3)

[15] International Atomic Energy Agency. The Management System for the Disposal of Radioactive Waste - Safety Guide. IAEA, Vienna, 2008 (Safety Stds Series No. GS-G-3.4)

[16] International Atomic Energy Agency. The Safety Case and Safety Assessment for the Disposal of Radioactive Waste - Specific Safety Guide. IAEA, Vienna, 2012 (Safety Standards Series No. SSG-23)

[17] Comissão Nacional de Energia Nuclear - CNEN. Gerência de Rejeitos Radioativos de Baixo e Médio Níveis de Radiação. CNEN NN 8.01, Rio de Janeiro, 2014

[18] Lichtenwalner, Charles P.(1992). Evaluation of wipe sampling procedures and elemental surface contamination. American Industrial Hygiene Association Journal, 53: 10, 657-659.

[19] E. Barren, S.B. Dorn, A.L. Ortiz, Jr., C.M. Penney, R.B. Sheldon, A.P. Shapiro, A.A. Bracco. Rapid Surface Sampling and Archival Record (RSSAR) System. Annals of a Conference on 'Industry Partnerships to Deploy Environmental Technology', held in Morgantown, West Virginia, October 22-24, 1996. DOE/MC/30174-97/C0821

[20] J R Verkouteren, J L Coleman, R A Fletcher,WJ Smith, G A Klouda, G Gillen. A method to determine collection efficiency of particles by swipe sampling. Meas. Sci. Technol. 19 (2008) 115101 (12pp).

[21] Stephen Billets. A Literature Review of Wipe Sampling Methods for Chemical Warfare Agents and Toxic Industrial Chemicals. EPA, 2007. (EPA/600/R-07/004)

[22] Applied Industrial Hygiene Chemistry Team. Evaluation guidelines for surface sampling methods. Industrial Hygiene Chemistry Division, OSHA. (T006-01-0104-M)

[23] Environmental Management Support. A Performance-Based Approach to the Use of Swipe Samples in Response to a Radiological or Nuclear Incident. USEPA, 2011 (EPA 600/R-11/122)

[24] Hitz B, Ewing JJ, Hecht J. Introduction to Laser Technology (3rd Edition). IEEE Press, New York, NY, USA (2001)

[25] United States Department of Energy. Quality Assurance Inspection and Testing of HEPA Filters. USDOE, 2007. (DOE-STD-3025-2007).

[26] V. P. Veiko, E. A. Shakhno, V. N. Smirnov, G. D. Nikishin and S. P. Rho. Laser Ablation and Local Deposition: Physical Mechanisms and Application for 
Decontamination of Radioactive Surfaces. Journal of the Korean Physical Society, Vol. 51, No. 1, July 2007, pp. 345-351.

[27] D. Grojo, A. Cros, P. Delaporte, M. Sentis. Time-of-flight measurements of ejected particles during dry laser cleaning. Appl. Phys. B 84, 517-221, 2006.

[28] Annemie Bogaertsa, Zhaoyang Chena, Renaat Gijbelsa, Akos Vertes. Laser ablation for analytical sampling: what can we learn from modeling? Spectrochimica Acta Part B 58 (2003) 1867-1893.

[29] TADDEI, Maria Helena Tirollo. Determinação de fatores de escala para estimativa do inventário de radionuclídeos em rejeitos de média e baixa atividades do reator IEA-R1. 2013. Tese (Doutorado em Tecnologia Nuclear Reatores) - Instituto de Pesquisas Energéticas e Nucleares, Universidade de São Paulo, São Paulo, 2013. doi:10.11606/T.85.2013.tde-25112013-155403. Acesso em: 2018-08-01

[30] V. Vitiello, S. Amoruso, A. Sambri, X. Wang, Appl. Surf. Sci. 252, 4712 (2006)

[31] Ph. Delaporte, M. Gastaud, W.Marine, M. Sentis, O. Uteza, P. Thouvenot, J.L. Alcaraz, J.M.Le Samedy, D. Blin. Dry excimer laser cleaning applied to nuclear decontamination. Appl. Surf. Sci. 208-209 (2003) 298-305.

[32] Bogaerts A, Chen Z, Gijbels R, Vertes A (2003) Laser ablation for analytical sampling: what can we learn from modeling? Spectrochim Acta B 58: 1867-1893

[33] L. Pierre, J.C. Dumont. Procede de controle de la contamination surfacique d'un solide et dispositif de mise en euvre. Organisation Mondiale de la Propriete Intellectuelle. WO 95/17656

[34] Massarani, G. Fluidodinâmica em Sistemas Particulados. 2. ed. Rio de Janeiro: e-papers, 2002. v. 01. 152p .

[35] WHITE, Frank M. Mecânica dos fluidos. 6.ed. Rio de Janeiro: McGrawHill, 2010. 880p. 
APÊNDICE I - DESENHO DE CONJUNTO DA SONDA 


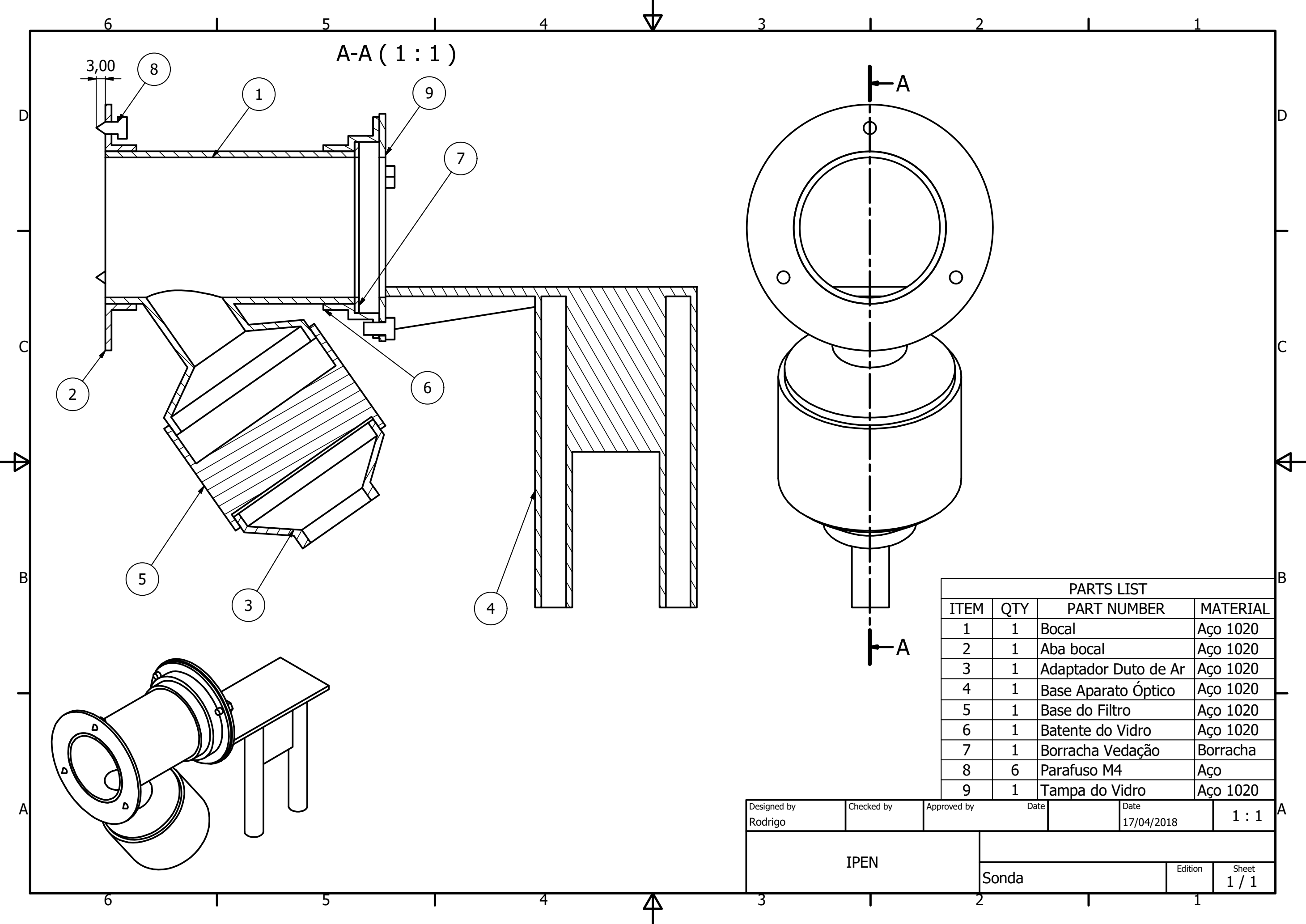


APÊNDICE II - DESENHOS DE FABRICAÇÃO DAS PEÇAS DA SONDA 


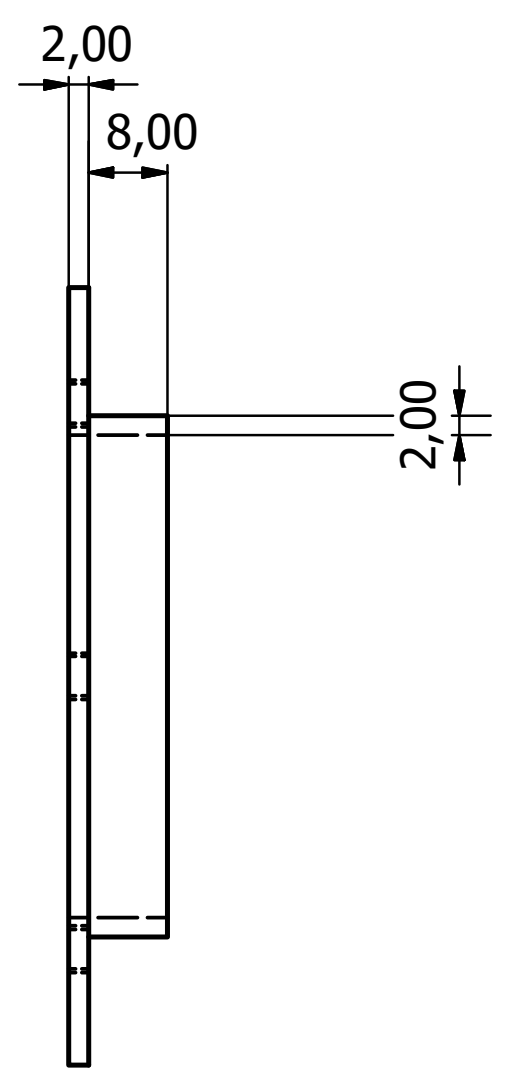

3 furos rosqueados

diâmetro $=4 \mathrm{~mm}$

passo $=0,7 \mathrm{~mm}$

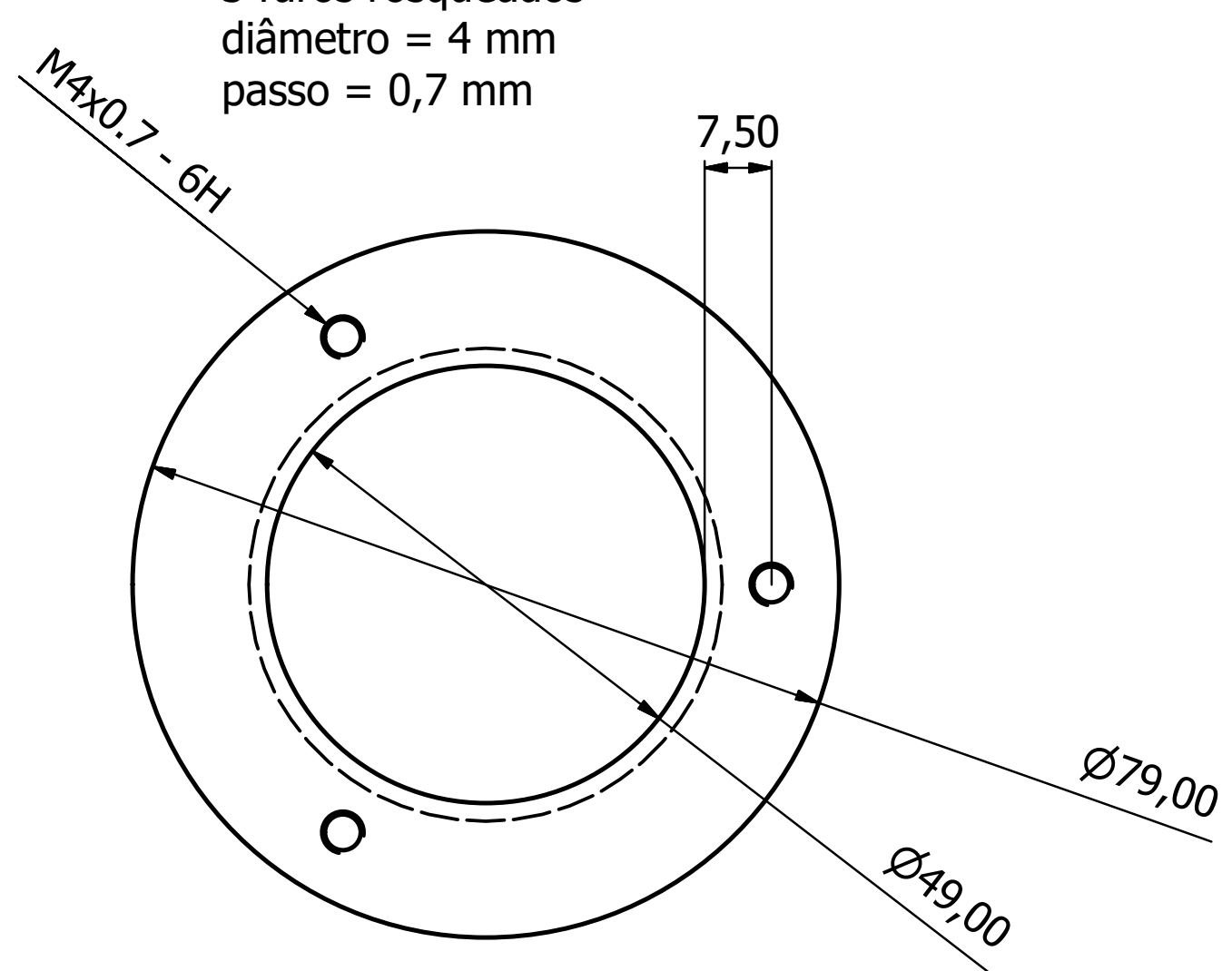

Furo interno de diâmetro 49,00 mm deve entrar com ajuste forçado (H7m6) na peça bocal.

\begin{tabular}{|l|l|l|l|l|l|}
\hline $\begin{array}{l}\text { Designed by } \\
\text { Rodrigo }\end{array}$ & \multicolumn{1}{|c|}{ Checked by } & Approved by & & $\begin{array}{l}\text { Date } \\
11 / 01 / 2018\end{array}$ & $1: 1$ \\
\hline \multirow{2}{*}{ IPEN } & \multicolumn{3}{|c|}{} \\
\cline { 2 - 5 } & Aba bocal & Edition & $\begin{array}{r}\text { Sheet } \\
1 / 1\end{array}$ \\
\hline
\end{tabular}




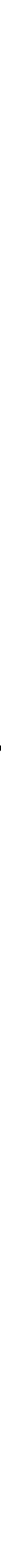




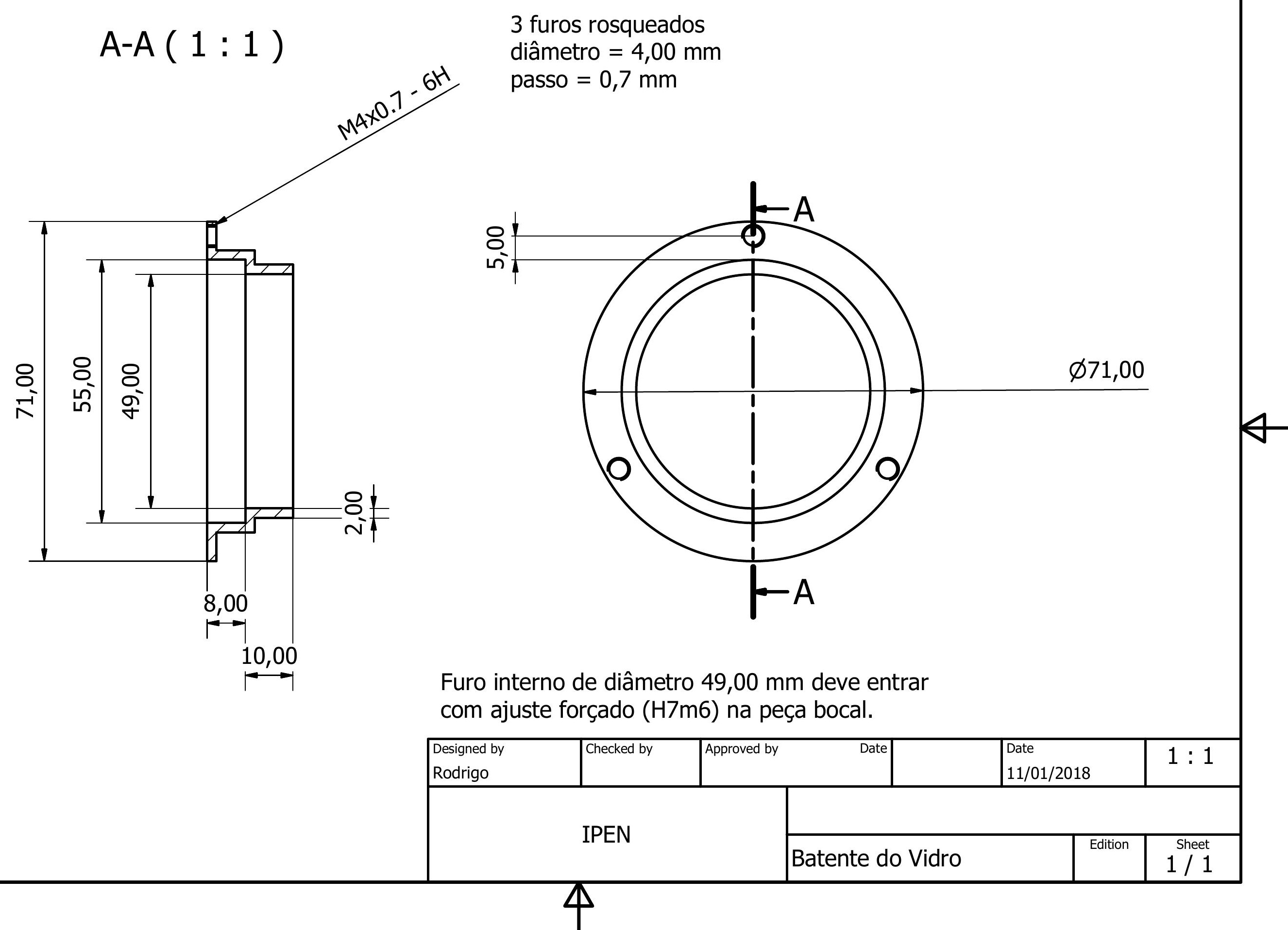



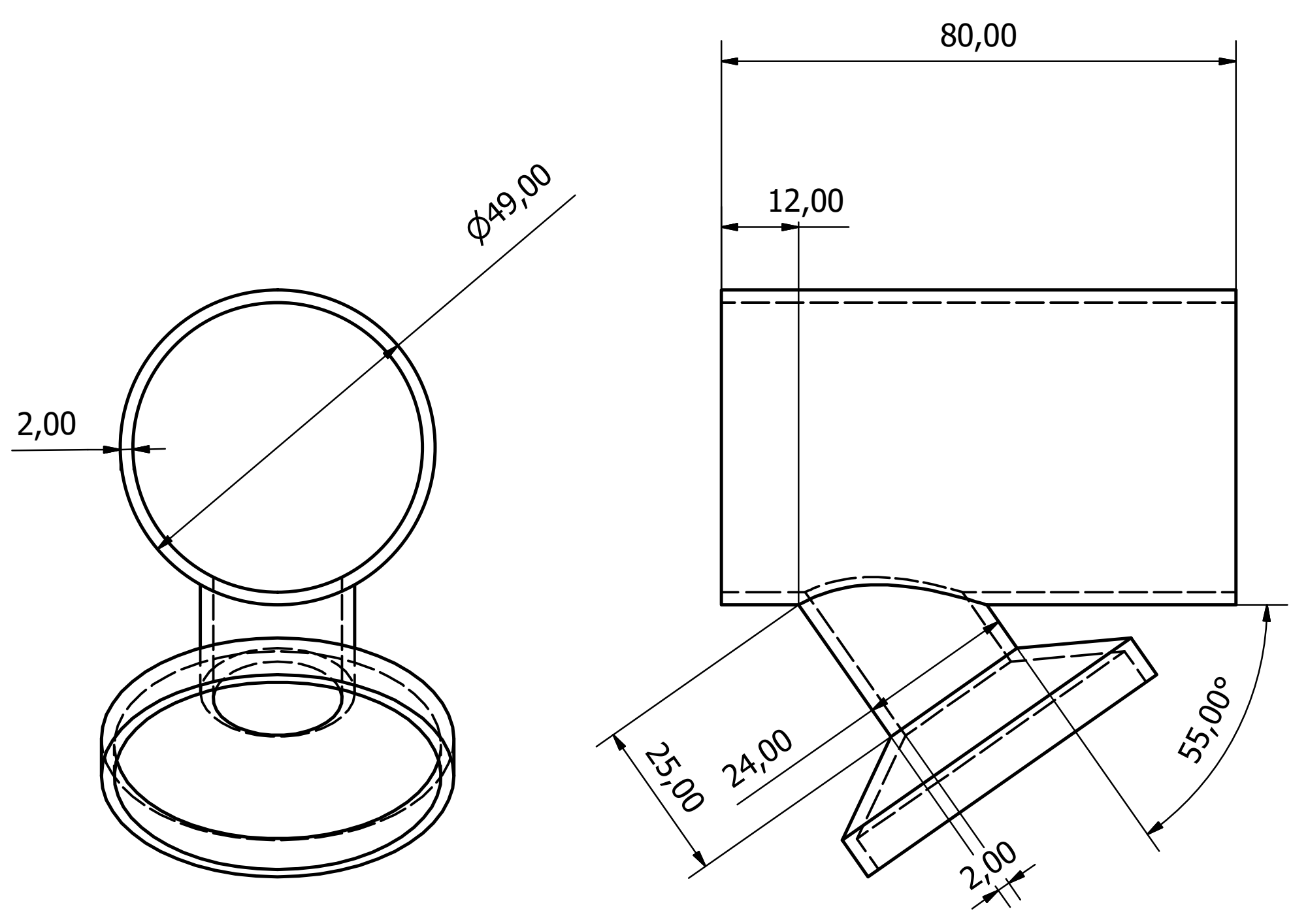

O tubo de diâmetro $24,00 \mathrm{~mm}$ deve ser cortado em um ângulo de $55^{\circ} \mathrm{e}$ soldado no tubo de diâmetro 49,00 mm

\begin{tabular}{|l|l|l|l|l|l|}
\hline $\begin{array}{l}\text { Designed by } \\
\text { Rodrigo }\end{array}$ & Checked by & \multicolumn{1}{|c|}{ Approved by } & & $\begin{array}{l}\text { Date } \\
16 / 04 / 2018\end{array}$ & $1: 1$ \\
\hline \multirow{2}{*}{ IPEN } & & \multicolumn{3}{|c|}{} \\
\cline { 2 - 5 } & Bocal & & Edition & $\begin{array}{r}\text { Sheet } \\
1 / 1\end{array}$ \\
\hline
\end{tabular}


A espessura da borracha de vedação pode

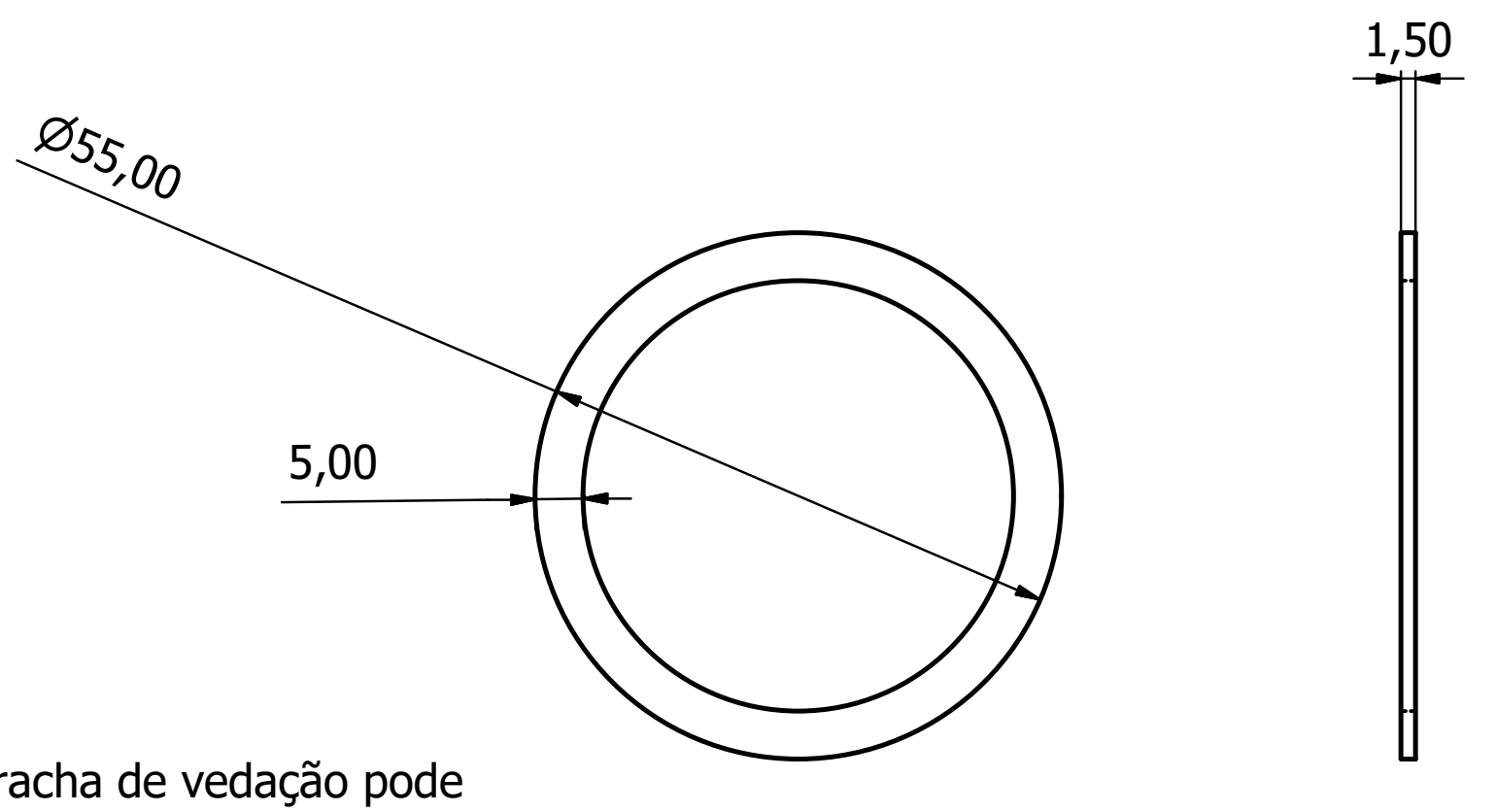

variar conforme a espessura do vidro

utilizado na traseira da sonda, sendo que a

soma das duas espessuras deve ser $9 \mathrm{~mm}$.

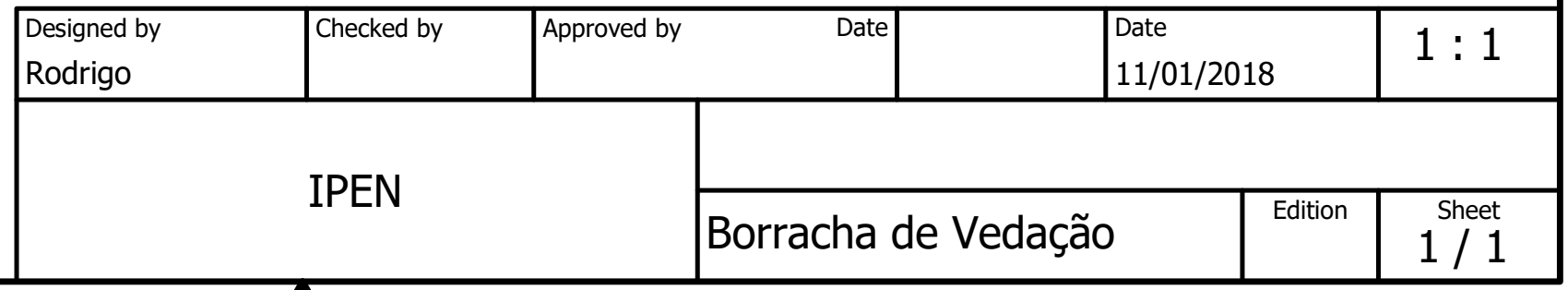



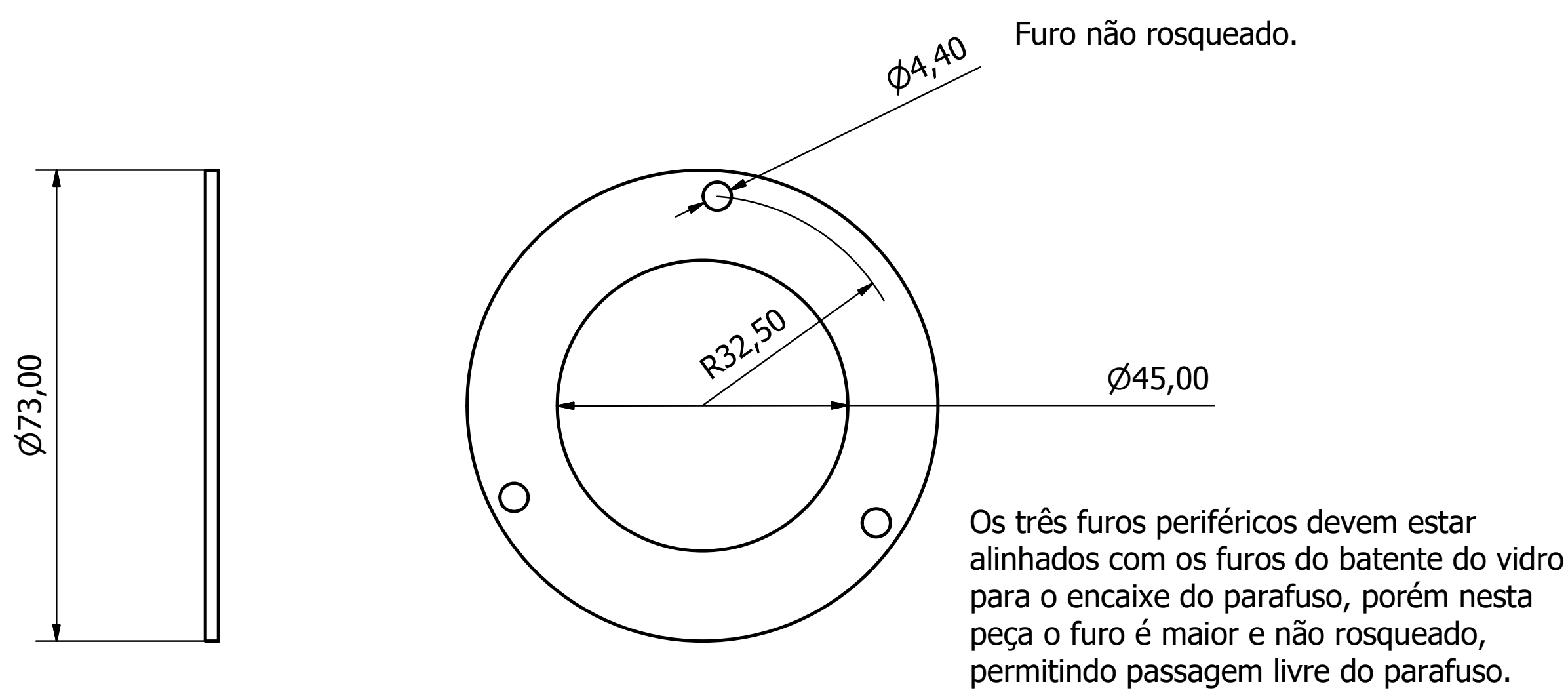

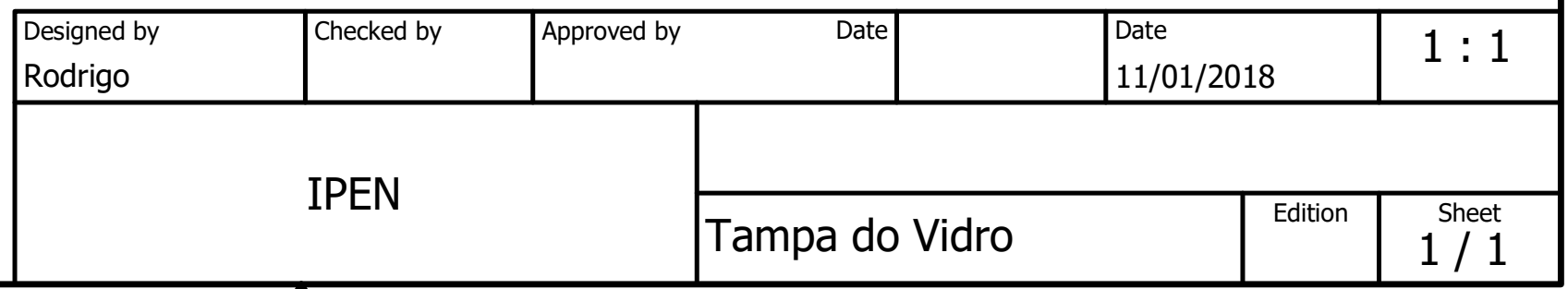




\section{INSTITUTO DE PESQUISAS ENERGÉTICAS E NUCLEARES}

Diretoria de Pesquisa, Desenvolvimento e Ensino

Av. Prof. Lineu Prestes, 2242 - Cidade Universitária CEP: 05508-000

Fone/Fax(0XX11) 3133-8908

SÃO PAULO - São Paulo - Brasil

http://www.ipen.br

O IPEN é uma Autaquia vinculada à Secretaria de Desenvolvimento, associada à Universiade de São Paulo e gerida técnica e administrativamente pela Comissão Nacional de Energia Nuclear, órgão do Ministério da Ciência, Tecnologia e Inovação. 